\title{
WestVirginiaUniversity
}

THE RESEARCH REPOSITORY @ WVU

Graduate Theses, Dissertations, and Problem Reports

2017

\section{Impact of formation damage due to perforation on well productivity}

\author{
Elmouzemill Abrahim Adam
}

Follow this and additional works at: https://researchrepository.wvu.edu/etd

\section{Recommended Citation}

Adam, Elmouzemill Abrahim, "Impact of formation damage due to perforation on well productivity" (2017). Graduate Theses, Dissertations, and Problem Reports. 3975.

https://researchrepository.wvu.edu/etd/3975

This Problem/Project Report is protected by copyright and/or related rights. It has been brought to you by the The Research Repository @WVU with permission from the rights-holder(s). You are free to use this Problem/Project Report in any way that is permitted by the copyright and related rights legislation that applies to your use. For other uses you must obtain permission from the rights-holder(s) directly, unless additional rights are indicated by a Creative Commons license in the record and/ or on the work itself. This Problem/Project Report has been accepted for inclusion in WVU Graduate Theses, Dissertations, and Problem Reports collection by an authorized administrator of The Research Repository @ WVU. For more information, please contact researchrepository@mail.wvu.edu. 


\title{
Impact of Formation Damage Due to Perforations on Well Productivity \\ Adam Elmouzemill
}

\begin{abstract}
Problem Report Submitted to the Benjamin M. Statler College of Engineering and Mineral Resources in partial fulfillment of the requirements for the degree of Master in Petroleum and natural Gas Engineering
\end{abstract}

\author{
Approved by \\ H. Ilkin. Bilgesu, Ph.D., Committee Chairperson \\ Sam Ameri, M.S. \\ Brijes Mishra, Ph.D. \\ Department of Petroleum and Natural Gas Engineering \\ 2017 Morgantown, West Virginia
}

Key words: Well completion, Perforation, Skin factor 


\section{Abstract}

Formation Damage can be defined as any reduction in near wellbore permeability which results from drilling, completion, production, injection, attempted stimulation or any other well intervention. In the majority of completions, once the reservoir has been drilled, production casing or a liner is run into the well and cemented in place. To provide the communication between the reservoir and the wellbore, it is necessary to perforate through the walls of the cemented casing or a liner and penetrate into the formation.

Currently horizontal well bores completed with extensive perforation are conducted as several clusters along the well bore. Perforation can lead to "skin damage", and impair the well productivity. Formation damage caused by perforation is undesirable but it intends to be analyzed to understand its impact on completions and production.

This study provides a comprehensive overview of the perforation process and its techniques with its application in oil and gas industry. Furthermore, it studies the impact of perforations on well productivity based on formation damage resulting from perforating and drilling or workover operations. The effects of perforation depth and shot density were compared for damaged and undamaged perforations. The results will show the relationship between well productivity and the perforation operations. 


\section{Dedication}

I would like to dedicate this work to my great parents, who never stop giving of themselves in countless ways, and to my teachers who taught me to think, understand and making me a better person in this world. Without them it won't be possible what I have achieved. 


\section{Acknowledgments}

I would like to thank Almighty God for making this report work possible and a successful one. I would also like to express my profound gratitude to my research advisor Dr. H. Ilkin Bilgesu for his guidance, assistance and at the same time for keeping me centered and able to remain focused on the goal I set for myself.

I strongly appreciate the support and advice from Professor. Sam Ameri, chair of Petroleum and Natural Gas Engineering Department. He has been father and friend throughout my study .I am also very grateful to my course director Dr. Kashy Aminian for his support and advice. My sincere gratitude also goes to Ms. Beverly Matheny for her friendly ambience and continuous help.

Furthermore, my sincere appreciation goes to Dr. Brijes Mishra for his participation in my research committee and his great support.

I am deeply indebted to my friends for their advice, encouragement, support and help. Without them, I could not have accomplished nearly as much.

Finally, my deepest gratitude goes to my family and their unflagging love and unconditional support throughout my life and my studies. 


\section{Table of Contents}

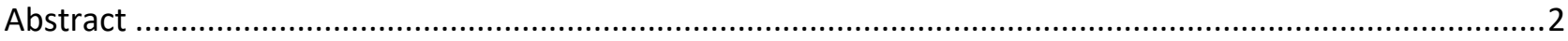

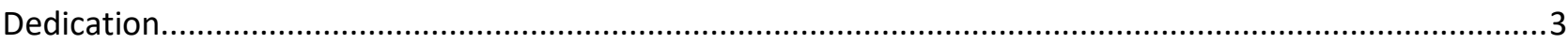

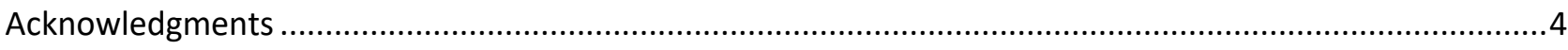

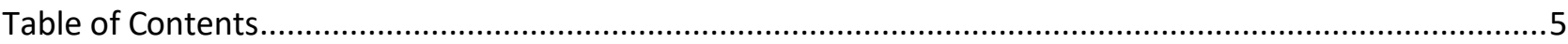

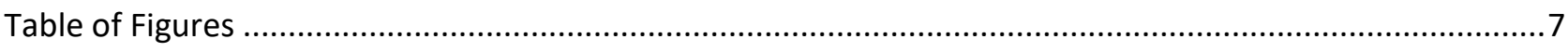

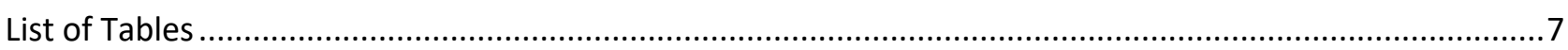

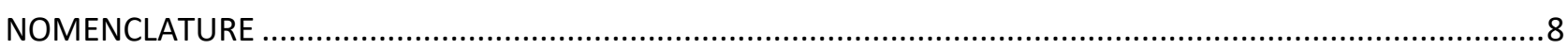

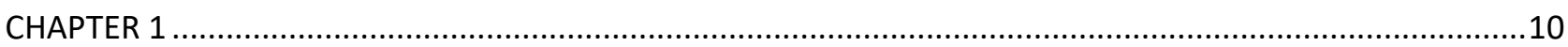

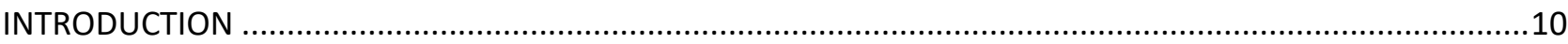

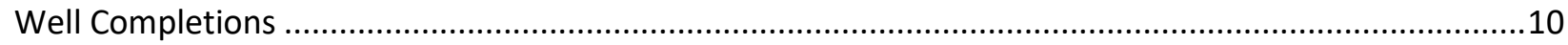

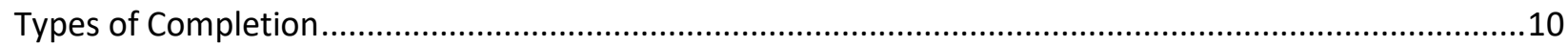

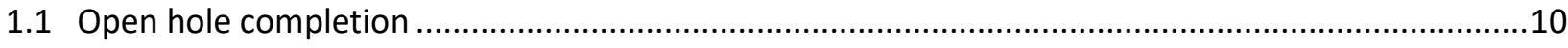

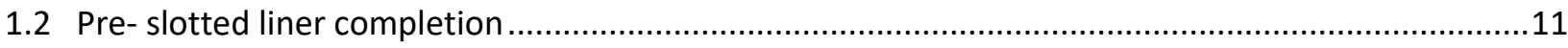

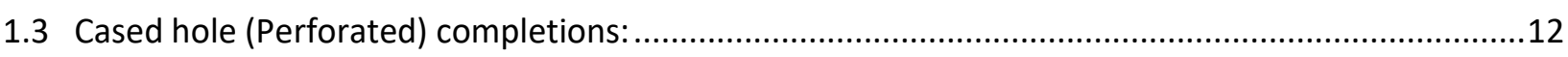

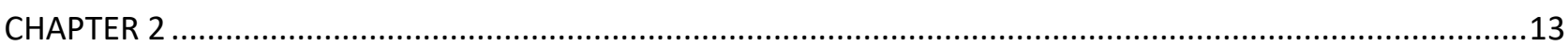

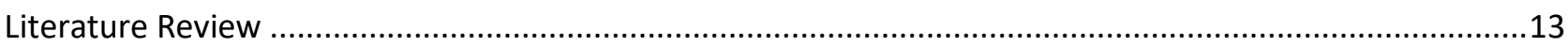

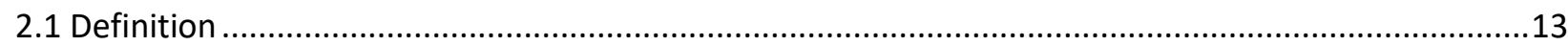

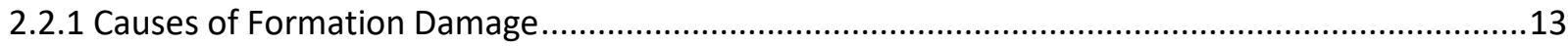

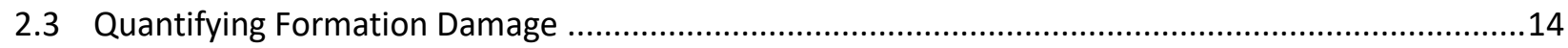

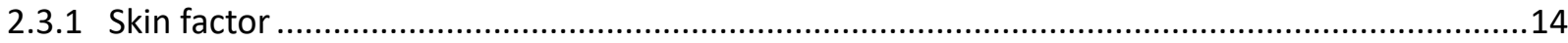

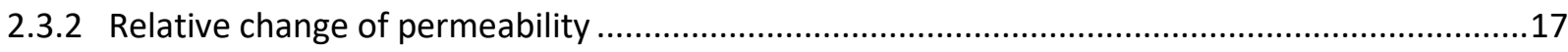

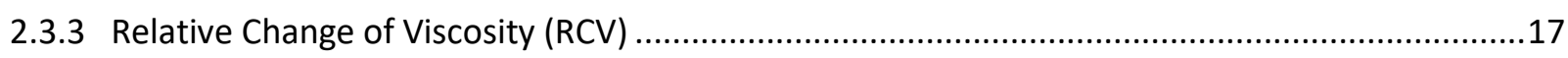

2.3.4 Relative Change of Effective Fluid Mobility (RCEM) ......................................................18

2.3.5 Relative Change of Flow Rate (RCFR) or Damage Ratio (DR) ............................................... 18

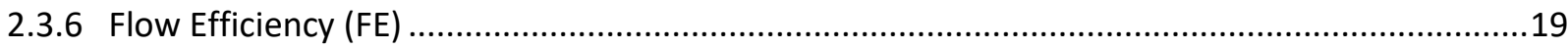

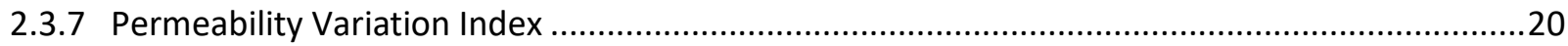

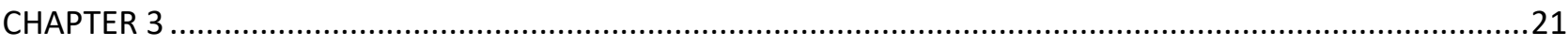

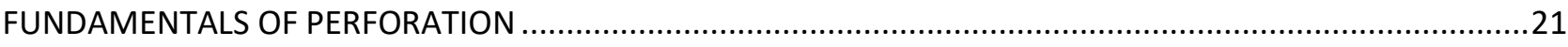

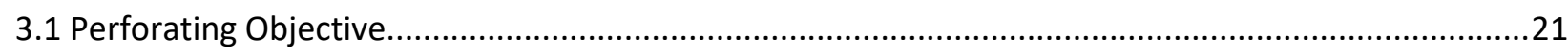

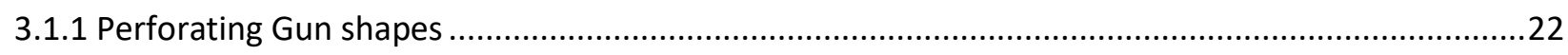

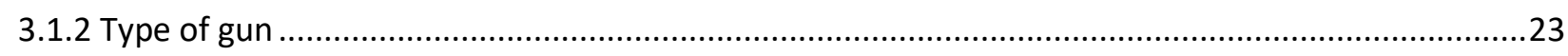

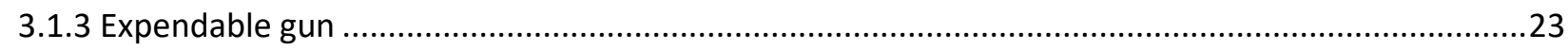

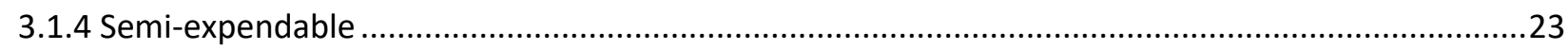

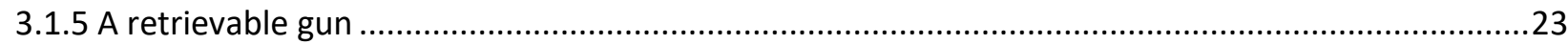




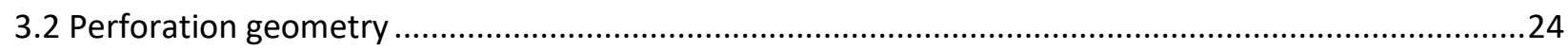

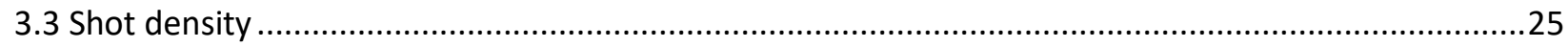

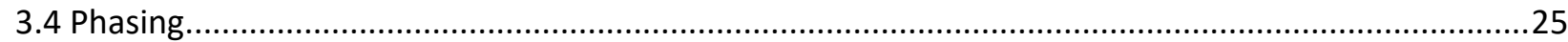

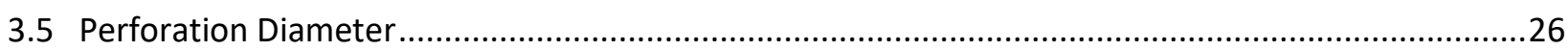

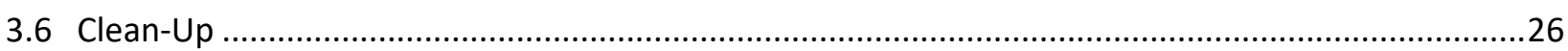

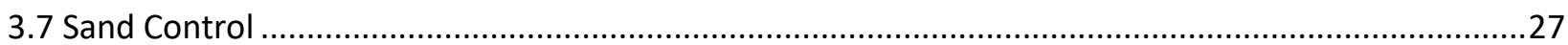

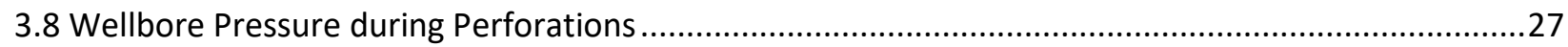

3.8.1 Overbalanced Perforating (Pwellbore > Preservoir) .................................................................28

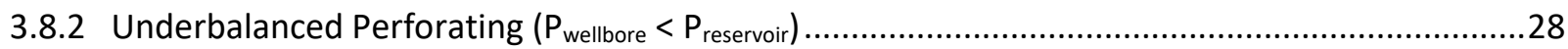

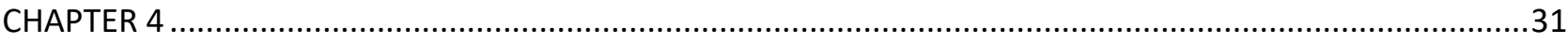

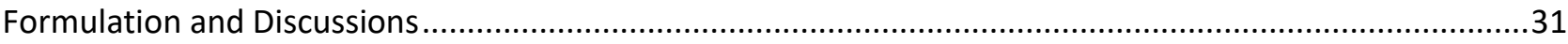

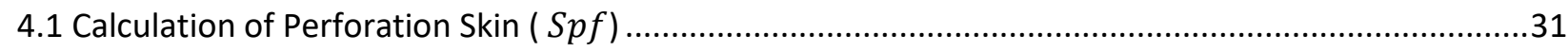

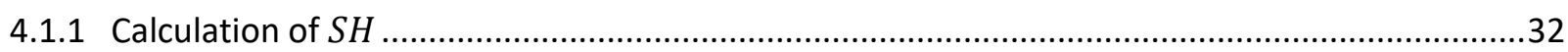

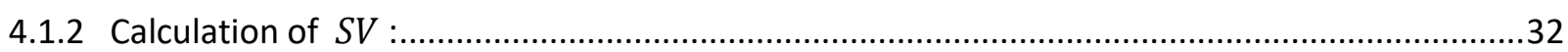

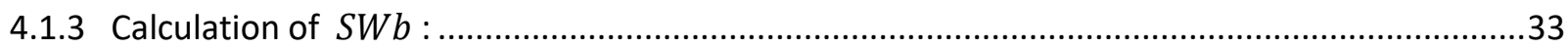

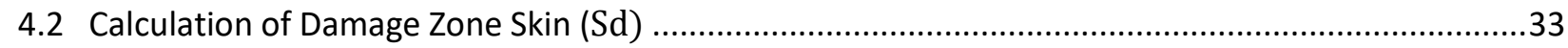

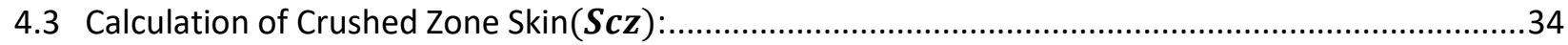

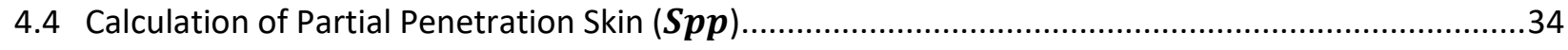

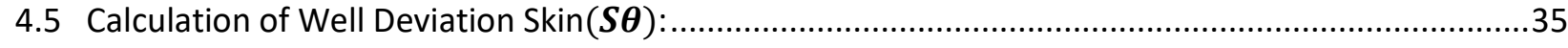

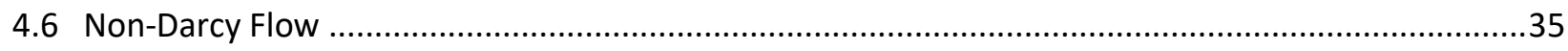

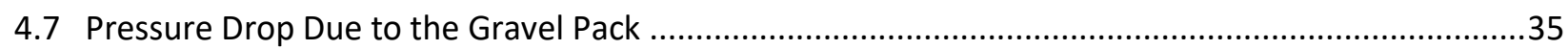

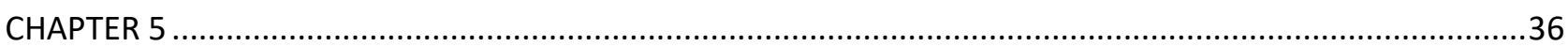

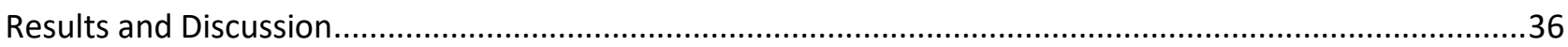

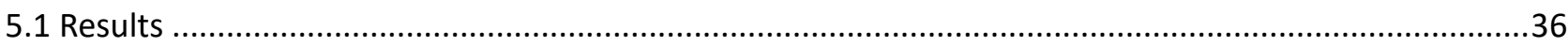

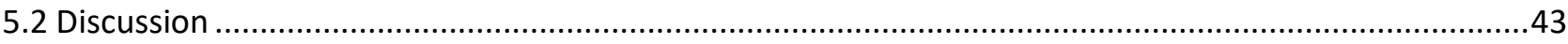

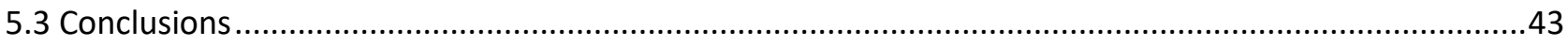

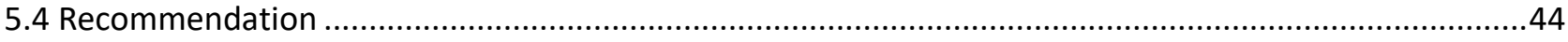

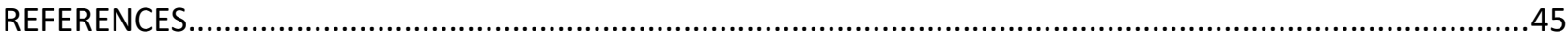

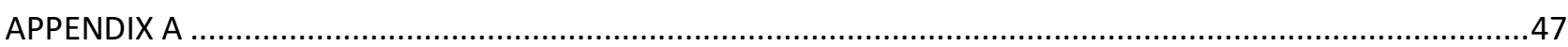

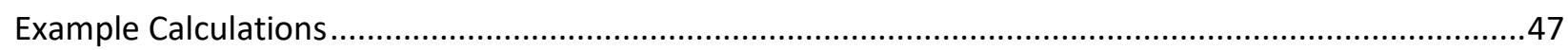

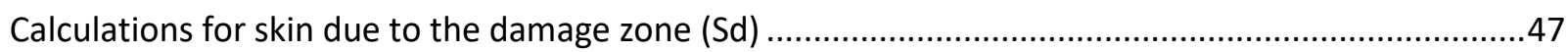

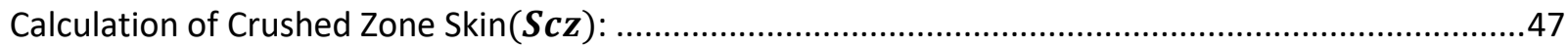

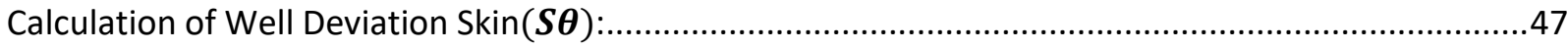




\section{Table of Figures}

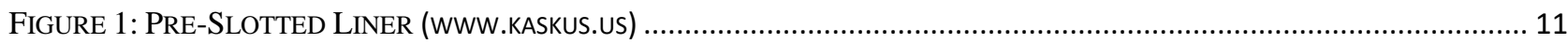

FIGURE 2: PERFORATED COMPLETION (WWW.KASKUS.US) ................................................................................. 12

FIGURE 3: PRESSURE PRofiLE IN THE NEAR-WELlBoRE REGION FOR AN IDEAL WELL AND A WELL WITH FORMATION DAMAGE ..................... 15

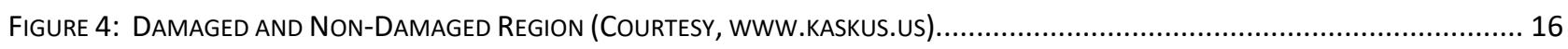

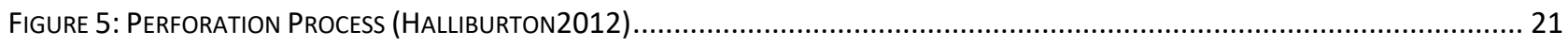

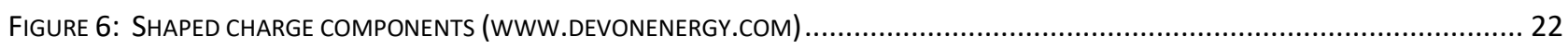

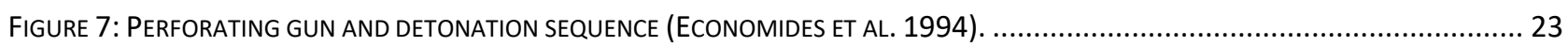

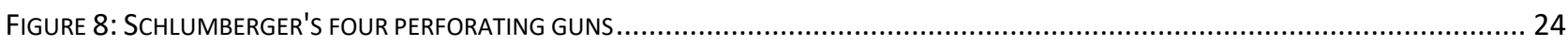

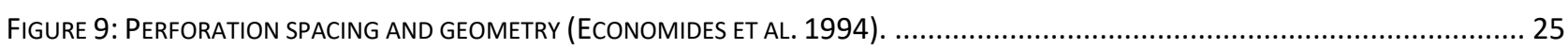

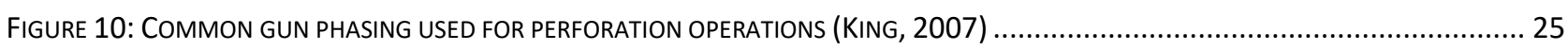

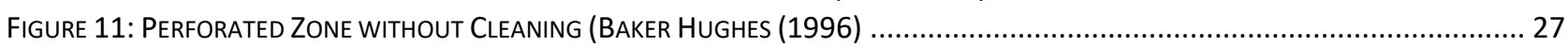

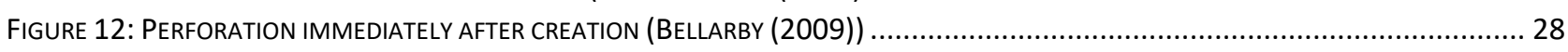

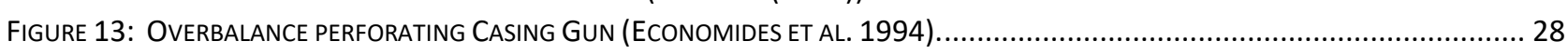

FIGURE 14: UNDERBALANCED PERFORATING CASING GUN (ECONOMIDES ET AL. 1994)............................................................... 29

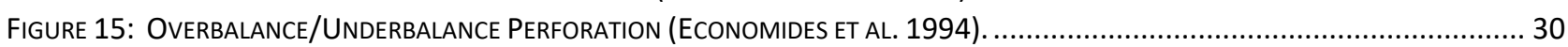

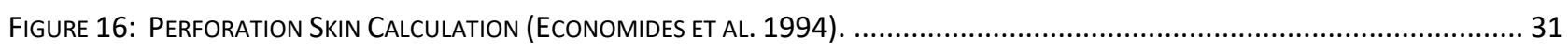

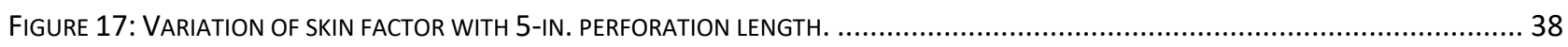

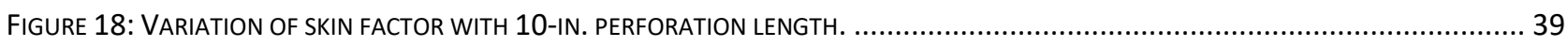

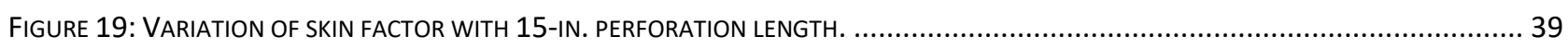

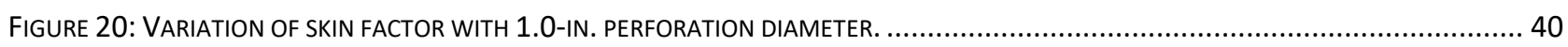

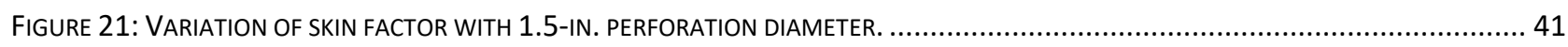

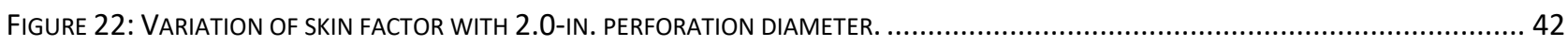

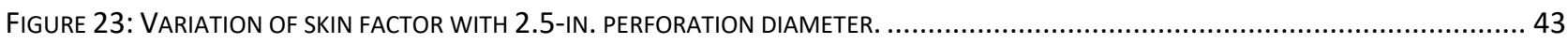

\section{List of Tables}

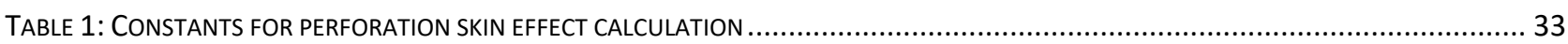

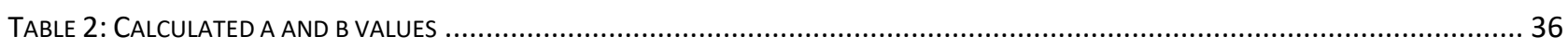

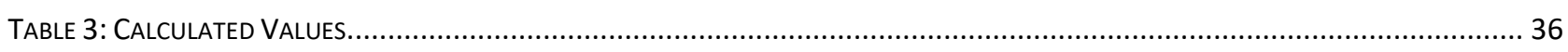

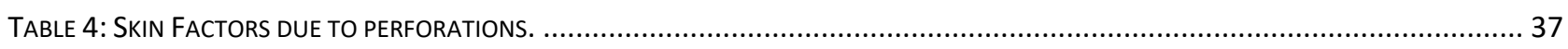

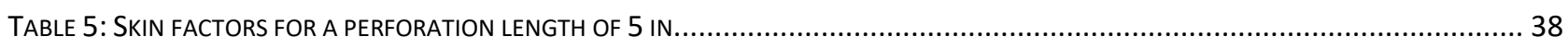

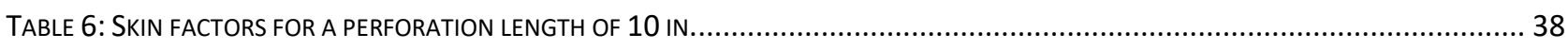

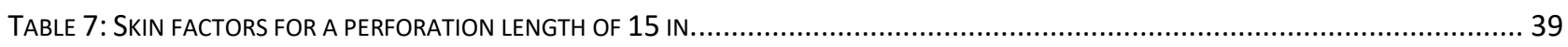

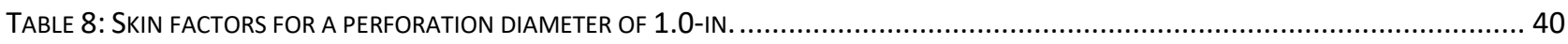

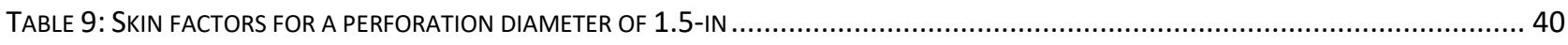

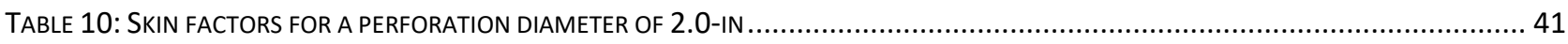

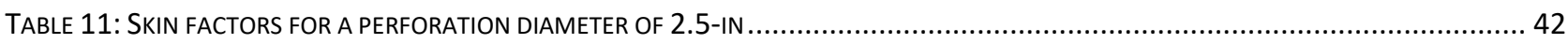


$K=$ permeability $(m d)$

\section{NOMENCLATURE}

$t=$ Time $($ hrs $)$

$\emptyset=$ Porosity $(\%)$

$\mu=$ Gas Viscosity (cp)

$C_{t}=$ Total compressibility (psi-1)

$r_{d}=$ Transient radius of drainage $(f t)$

$r_{w}=$ Wellbore radius $(f t)$

$m($ pi $)=$ Initial pseudo-pressure $($ psi2/cp $)$

$m\left(p_{w f}\right)=$ Bottomhole pseudo-pressure $(p s i 2 / c p)$

$m\left(p_{R}\right)=$ Reservoir pseudo-pressure $(p s i 2 / c p)$

$h=$ Formation thickness $(f t)$

$T=$ Temperature $(R)$

$q=$ Flow rate $(M s c f / D)$

$S=$ Apparent skin factor

$S=$ Skin factor

$\mu_{i}=$ Initial gas Viscosity $(\mathrm{cp})$

$D=$ Non-Darcy turbulence coefficient (Mscf/D)-1

$\bar{\mu}=$ Average gas Viscosity (cp)

$\gamma_{g}=$ Gas specific gravity

$t_{D}=$ Dimensionless time

$P=$ Pressure $($ Psia $)$

$z=$ Gas compressibility factor

$S-S_{f}=S_{d}=$ Damaged skin

$D_{f}=$ Non-Darcy flow factor for fractured wells

$D_{w}=$ Non-Darcy flow factor for nonfractured wells

$\propto=$ Factor

$\beta=$ Coefficient of internal resistance

$\rho=\operatorname{Density}(\mathrm{lbm} / \mathrm{ft} 3)$

$l_{p}=$ Perforation lngth (through the formation)

$r_{p}=$ perforation radius (assumes constant hole size along perforation)

$K_{c}=$ Crushed zone permeability

$l_{d}=$ Damaged zone length 
$\frac{k_{v}}{k_{h}}=$ Vertical to horizontal permeability ratio

$r_{c}=$ Crushed zone radius around perforation

$q=$ flow rate, $S T B /$ Day 


\section{CHAPTER 1}

\section{INTRODUCTION}

\section{Well Completions}

The drilling of a well is only the first stage in the total life of a well. Following the drilling, the well must be "completed" in order to produce hydrocarbons at a commercial rate. When we take a close look at the drilling processes, we can understand why completions are so important, when a well is drilled the formation is first crushed by the drill bit, then invaded by the drilling fluid. After drilling, the formation is surrounded by steel casing and weighted cement is pumped into the casing/formation annulus to bond the casing to the formation. After all of this, the target formation will need a little help if it is expected to produce hydrocarbons. To reduce the effects of the drilling process, specialized services are called upon to prepare the formation for production. The main objective of the completion is to enhance or maximize the production, which is usually modeled by the fundamental Darcy equation in the following radial flow system:

$$
\mathrm{q}=\frac{7.08 \times 10^{-3} k h\left(P_{e}-P_{w}\right)}{\mu \beta\left[\ln \left(\frac{r_{e}}{r_{w}}\right)+\mathrm{S}\right]}
$$

\section{Types of Completion}

The initial step in determining what type of completion is required is based on the well design. "How will the well be drilled?" is the first question to be answered. Once the type of well to be drilled has been decided upon, it is time to determine which the type of completion will satisfy the production requirements for that particular well. Although nowadays there are many different types of completion, which can be summarized into three basic categories; Open hole Completion, pre Slotted Liner Completion and cased Hole Completion

\subsection{Open hole completion}

Open hole completions provide large area of formation for production. Casing is set just above the reservoir and production tubing is run into the casing. Hydrocarbons are then produced directly into the bore hole, which flow into the tubing and then to the surface. This type of completion has two important advantages; 1) it is cheap and simple to operate, and 2) hydrocarbons will flow into the bore hole throughout its 360 degree circumference (radial flow). However, several drawbacks are readily apparent: 
- Hydrocarbons must pass through the damaged portion of the bore hole wall, which includes any filter cake

- As the hydrocarbons are produced, the formation (and bore hole) must be able to withstand the loss of fluids and be strong enough not to collapse.

- If the open hole extends past the reservoir, it is impossible to isolate flow from just the reservoir. Unwanted fluids (gas or water) can be produced from other formations or from the same formation (if the oil/water contact is exposed).

If well stimulation or workover is necessary, expensive isolation procedures will be required.

\subsection{Pre-slotted liner completion}

As seen in Figure 1 below, Pre- Slotted liner is a popular sand control screen in long horizontal completions and low productivity wells. The primary purpose of the slotted liner is preventing hole collapse in formations that may tend to cave in after being drilled, or as the formation pressure depletes.

Slotted liners may be hung from liner hangers or production packers. In some cases, the upper portion of the liner through the build section may be cemented to seal off a gas cap or problem zone above the payzone.

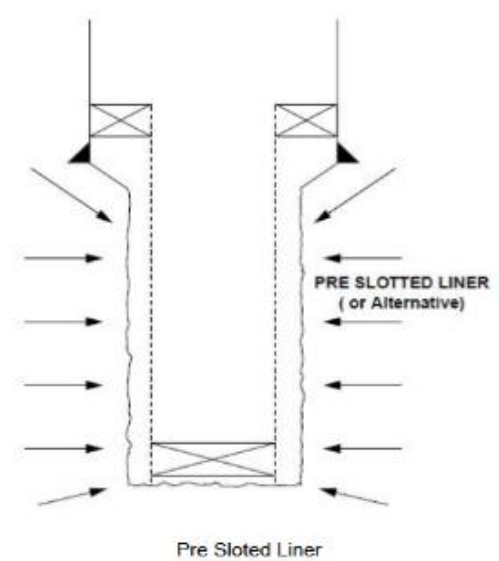

Figure 1: Pre-Slotted Liner (www.kaskus.us) 


\subsection{Cased hole (Perforated) completions:}

The well is drilled all the way through the producing zone and the production casing is lowered and cemented as seen in Figure 2. The casing is then perforated across the producing zone to establish communication between the formation and the well.

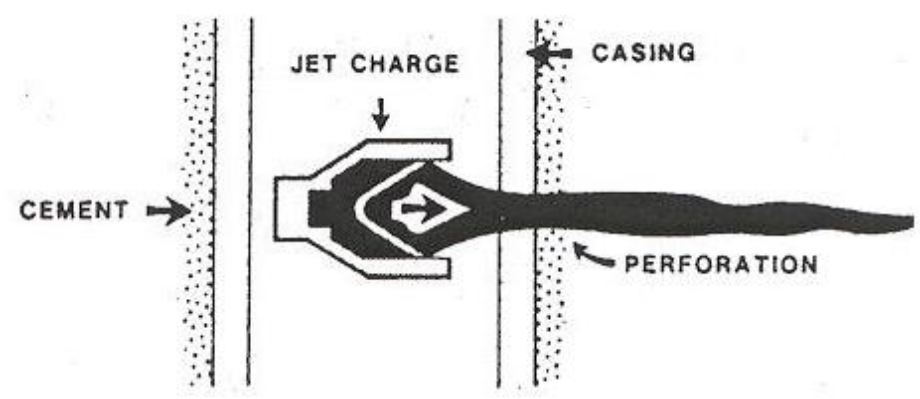

Figure 2: Perforated Completion (www.kaskus.us) 


\section{CHAPTER 2}

\section{Literature Review}

Many early studies ignored the damage around the perforation tunnel and focused on the importance of length and entrance hole diameter. Putting damage effects aside, the length of the perforation tunnel is theoretically the most critical factor in a natural completion in which no further stimulation or sand control is planned. Entrance hole diameter becomes more important when some sand control completion designs are planned. Because of the early studies that ignored the effects of formation damage, the primary selling points of perforating charges became perforated length and entrance hole diameter. These two elements diminish in significance when the effect of formation damage is studied.

\subsection{Definition}

Formation damage as a generic terminology referring to the impairment of the permeability of petroleum bearing formations by various adverse processes. It is an undesirable operational and economic problem that can occur during the various phases of oil and gas recovery from subsurface reservoirs including drilling, production, hydraulic fracturing, and workover operations. As expressed by Amaefule et al. (1988). "Formation damage is an expensive headache to the oil and gas industry." Bennion (1999) described formation damage as: "The impairment of the invisible, by the inevitable and uncontrollable, resulting in an indeterminate reduction of the unquantifiable!" Formation damage assessment, control, and remediation are among the most important issues to be resolved for efficient exploitation of hydrocarbon reservoirs.

\subsubsection{Causes of Formation Damage}

Amaefule et al. (1988) classified the various factors causing formation damage as following:

- Invasion of foreign fluids, such as water and chemicals used for improved recovery, drilling mud invasion, and workover fluids;

- Invasion of foreign particles and mobilization of indigenous particles, such as sand, mud fines, bacteria, and debris;

- Operation conditions such as well flow rates and wellbore pressures and temperatures;

- Properties of the formation fluids and porous matrix. Amaefule et al. (1988) further grouped these factors in two categories: 
1. Alteration of formation properties by various processes, including permeability reduction, wettability alteration, lithology change, release of mineral particles, precipitation of reaction-by products, and organic and inorganic scales formation

2. Alteration of fluid properties by various processes, including viscosity alteration by emulsion block and effective mobility change.

\subsection{Quantifying Formation Damage}

Formation damage can be quantified by various terms as presented by various authors include skin factor, relative change of permeability, relative change of viscosity, relative change of effective fluid mobility, relative change of flow rate (damage ratio), flow efficiency, and depth of damage.

\subsubsection{Skin factor}

The skin concept was introduced to the petroleum industry by van Everdingen , 1953) to account for differences in observed and calculated bottomhole pressures. It is currently widely used in the industry to measure or monitor impairment or improvement in well performance. They noticed that for a given flow rate, the measured bottom hole pressure was less than that calculated theoretically. This indicated that there was an additional pressure drop to a small zone of changed or reduced permeability around the wellbore and called this "invaded zone", or damaged zone, a skin zone. They suspected that invaded zone is due to reservoir contamination by mud and plugging of some pore spaces around the wellbore (Figure 3).

In general, the skin factor in wells can vary from +1 to +10 , and even higher values are possible. The skin factor is a dimensionless parameter relating the apparent (or effective) and actual wellbore radii according to the parameters of the damaged region (Hawkins, 1956):

Mathematically skin pressure drop is presented by,

$$
S=\frac{k h(\Delta p) s k i n}{141.2 q \mu_{o} \beta_{o}}
$$




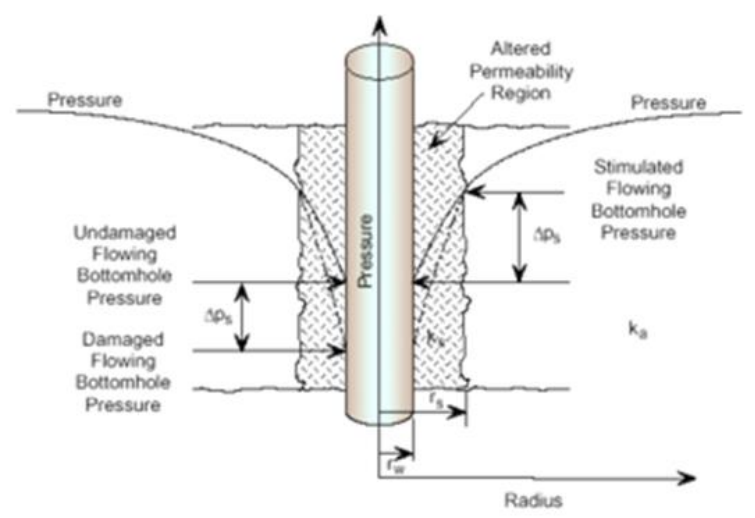

Figure 3: Pressure profile in the near-wellbore region for an ideal well and a well with formation damage

(Courtesy, www.kaskus.us)

The concept of thin skin in the above equation works well in damaged wells but because of mathematical and physical difficulties when the well is stimulated i.e. negative skin, it has to be generalized.

Hawkins modified the above equation by introducing the concept of thick skin. He defined the skin factor for damaged zone of radius rs with permeability kd in a formation with permeability, $\mathrm{k}$, and wellbore radius, $r_{w}$

$$
s=\left(\frac{k}{k_{d}}-1\right) \ln \left(\frac{r_{d}}{r_{w}}\right)
$$

Equation 2-1 is known as Hawkins formula. From the equation it can be deduced that $\mathrm{If} k<k$ the well is damaged and $s>0$; conversely, if $k \mathrm{~d}>k$, then $s<0$ and the well is stimulated. For $s=0$, the near-wellbore permeability is equal to the original reservoir permeability.

Generally, certain well logs may enable calculation of the damaged radius, $r_{d}$, whereas pressure transient analysis may provide the skin effect, $s$, and reservoir permeability, $k$. Equation 2.1 may then be used to calculate the value of the altered permeability $k \mathrm{~d}$ (Figure 4). 


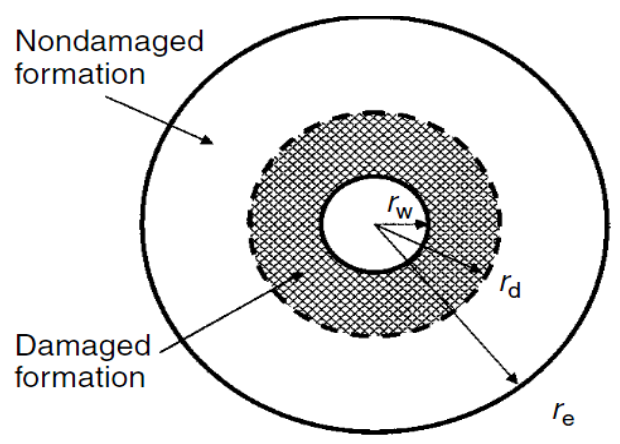

Figure 4: Damaged and Non-Damaged Region (Courtesy, www.kaskus.us)

In the absence of production log data, Frick and Economides postulated that, an elliptical cone is a more plausible shape of damage distribution along a horizontal well. They developed a skin effect expression, analogous to the Hawkins formula:

$$
s_{e q}=\left(\frac{k}{k_{d}}-1\right) \ln \left[\frac{1}{I_{a n i}+1}\right] \sqrt{\frac{4}{3}\left(\frac{a_{S H, \text { max }}^{2}}{r_{w}^{2}}+\frac{a_{S H, \text { max }}}{r_{w}}+1\right)}
$$

Where $S_{e q}$ is the equivalent skin effect, $I_{a n i}$ is the index of anisotropy and $a_{S H, \max }$ is the horizontal axis of the maximum ellipse, normal to the well trajectory. The maximum penetration of damage is near the vertical section of the well. They stated that the shape of the elliptical cross-section will depend greatly on the index of anisotropy. The index of anisotropy $I_{a n i}$ is defined as:

$$
I_{a n i}=\sqrt{\frac{K_{H}}{K_{V}}}
$$

With $K_{H}$ being the horizontal permeability and $K_{V}$ is the vertical permeability.

Piot and Lietard expressed the total skin of a well as a sum of the pseudo skin of flow lines from the formation face to the pipeline and the true skin due to formation damage. Economides and Nolte shown that the total skin effect is a composite of a number of factors, most of which usually cannot be altered by conventional matrix treatments.

The total skin effect may be written as:

$$
s_{t}=s_{c+\theta}+s_{p}+s_{d}+\sum \text { pseudoskins }
$$


The last term in the right-hand side of Eq. 2.4 represents an array of pseudoskin factors, such as phase-dependent and rate-dependent effects that could be altered by hydraulic fracturing treatments. The other three terms are the common skin factors. The third term $s d$ refers to the damage skin effect as defined in equation 2.1. The first term $s c+\theta$ is the skin effect caused by partial completion and slant. Documented a detailed approach of estimating the skin factor due to partial completion and slant. The parameters needed for the estimation are: completion thickness, reservoir thickness, elevation, and penetration ratio. An example illustrating the calculation of this skin effect is documented by Economides and Nolte. The second term $s p$ represents the skin effect resulting from perforations. It is described by Harris and also expounding the concept, Karakas and Tariq have shown that:

$$
s_{p}=s_{H}+s_{V}+s_{w b}
$$

\subsubsection{Relative change of permeability}

The relative change of permeability expresses the change of formation permeability by nearwellbore damage as a fraction, given by

$$
\mathrm{RCP}=\frac{K-K_{\mathrm{d}}}{K}=1-\frac{K_{\mathrm{d}}}{K}
$$

Where $\mathrm{K}$ and $K_{d}$ denote the formation permeability before and after damage, respectively.

$$
\mathrm{PCP}=\left[1-\frac{K_{\mathrm{d}}}{K}\right] \times 100
$$

\subsubsection{Relative Change of Viscosity (RCV)}

The relative change of viscosity expresses the change of fluid viscosity by various processes, such as emulsification, defined by

$$
\mathrm{RCV}=\frac{\mu-\mu_{\mathrm{d}}}{\mu}=1-\frac{\mu_{\mathrm{d}}}{\mu}
$$

Where $\mu$ and $\mu \mathrm{d}$ denoted the fluid viscosities before and after fluid damage, respectively, the percent change of viscosity is defined by

$$
\mathrm{PCV}=\left[1-\frac{\mu_{\mathrm{d}}}{\mu}\right] \times 100
$$




\subsubsection{Relative Change of Effective Fluid Mobility (RCEM)}

The decline of productivity of wells in asphaltic reservoirs is usually attributed to the reduction of the effective mobility of oil by various factors (Amaefule et al., 1988). The effective mobility of oil is a convenient measure of oil flow capability in a porous formation because it combines the three relevant properties in one group as

$$
\lambda=\frac{K_{\mathrm{e}}}{\mu}=\frac{K k_{\mathrm{r}}}{\mu}
$$

Where $\mathrm{K}$ is the permeability of the reservoir formation, and $\mathrm{Ke}, \mathrm{kr}$ and $\mu$ are the effective permeability, relative permeability, and viscosity of a fluid phase, respectively. The relative change of effective fluid mobility is defined by

$$
\operatorname{RCEM}=\frac{\lambda-\lambda_{\mathrm{d}}}{\lambda}=1-\frac{\lambda_{\mathrm{d}}}{\lambda}
$$

Where $\lambda$ and $\lambda d$ are the effective fluid mobility before and after the fluid and/or formation damage.

\subsubsection{Relative Change of Flow Rate (RCFR) or Damage Ratio (DR)}

The RCFR or DR express the change of well flow rate by near-wellbore damage as a fraction, given by (Amaefule et al., 1988)

$$
\mathrm{DR} \equiv \mathrm{RCFR}=\frac{q-q_{\mathrm{d}}}{q}=1-\frac{q_{\mathrm{d}}}{q}
$$

Where $\mathrm{q}$ and qd denote the undamaged and damaged standard flow rates, respectively. The production loss by alteration of formation properties can be formulated as follows. The theoretical undamaged and damaged flow rates for a steady-state incompressible radial flow in a homogeneous and isotropic porous media are given, respectively, by (Amaefule et al., 1988)

$$
\begin{gathered}
q=\frac{2 \pi K h\left(p_{\mathrm{e}}-p_{\mathrm{w}}\right)}{\mu B \ln \left(r_{\mathrm{e}} / r_{\mathrm{w}}\right)} \\
q_{\mathrm{d}}=\frac{2 \pi K h\left(p_{\mathrm{e}}-p_{\mathrm{w}}\right)}{\mu B\left[\ln \left(r_{\mathrm{e}} / r_{\mathrm{d}}\right)+\left(K / K_{\mathrm{d}}\right) \ln \left(r_{\mathrm{d}} / r_{\mathrm{w}}\right)\right]}
\end{gathered}
$$


Therefore, substituting Equation (2-13) and (2-14), Eq. (2-12) yields the following expression for the damage ratio:

$$
D R=\frac{\left(k / k_{d}-1\right) \ln \left(r_{d} / r_{w}\right)}{\left(k_{k_{d}}\right) \ln \left(r_{e} / r_{d}\right)+\ln \left(r_{d} / r_{e}\right)}
$$

Where $\mu$ and $\mathrm{B}$ are the fluid viscosity and formation volume factors. $\mathrm{K}$ and $\mathrm{Kd}$ are the undamaged and damaged effective permeability, $h$ is the thickness of the effective pay zone, $p w$ and pe are the wellbore and reservoir drainage boundary fluid pressures, rw and re are the wellbore and reservoir drainage radii, and $\mathrm{rd}$ is the radius of the damaged region. The effective skin factor, $\mathrm{s}$, is defined by ( Hawkins, 1959)

$$
s=\left(\frac{k}{k_{d}}-1\right) \ln \left(\frac{r_{d}}{r_{w}}\right)
$$

Thus, substituting Eq. (2-16) into Eq. (2-15) yields the relationship between the damage ratio and the skin factor as

$$
D R=\frac{s}{s+\ln \left(r_{e} / r_{w}\right)}
$$

\subsubsection{Flow Efficiency (FE)}

Flow efficiency (FE) is the ratio of the damaged to undamaged formation flow (production or injection) indices (FI):

$$
F E=\frac{F I_{d}}{F I}=\frac{\bar{p}-p_{w f}-\Delta p_{s}}{\bar{p}-p_{w f}}
$$

Where $\bar{p}$ and $p_{w f}$ denote the average reservoir fluid and flowing well bottomhole pressures, respectively, and $\Delta \mathrm{P} s$ is the additional pressure loss by the skin effect. The flow efficiency of vertical wells for radial and incompressible fluid flow at a steady-state condition is given by (Mukherjee and Economides, 1991)

$$
F E_{\mathrm{v}}=\frac{\ln \left(r_{\mathrm{e}} / r_{\mathrm{w}}\right)}{s+\ln \left(r_{\mathrm{e}} / r_{\mathrm{w}}\right)}
$$




\subsubsection{Permeability Variation Index}

Civan (2007) presented an index which can be used to express the variation in permeability due to nearwellbore damage. This index known as permeability variation (or reduction) index can be expressed mathematically as:

$$
P V I=\frac{K-K_{d}}{K}=1-\frac{K_{d}}{K}
$$

Where $K$ and $K d$ denote the formation permeability before and after damage, respectively. 


\section{CHAPTER 3}

\section{FUNDAMENTALS OF PERFORATION}

Perforations are holes that are punched through the casing and cement, and extend some distance into the formation. The main purpose of perforating the casing or liner of a well is to form a path through which fluids will flow between reservoir and borehole (Figure 5). It is important that the gun properties such as shot per foot, phasing and charge type are considered in designing perforation because these factors are what determine if the operation will be successful or cause damage. Perforating is a vital part of well completion operations thus if it is incorrectly carried out, the productivity of the well will appear to be low, which may result in individual productive zones or even an entire field being mistakenly condemned and possibly abandoned.

According to Behrmann et al. (1997) "The economic value of an oil and gas well depends on the connection between the wellbore and the formation which is done by perforation. The completion and production engineers have three key objectives: allow the oil into the well, where it can flow naturally or be pumped to the surface; exclude water from overlying and underlying units and keep any rock formation particles out of the well". The objective of this chapter is to investigate the perforation process and its different methods leading to perfect penetration.

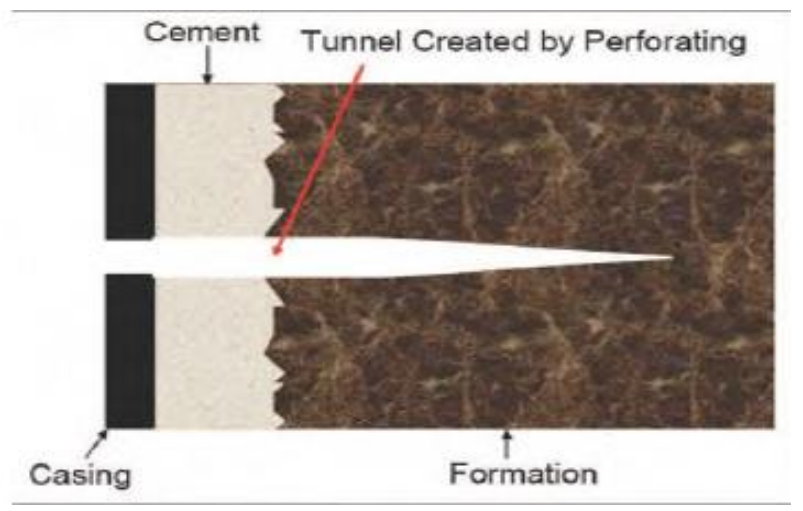

Figure 5: Perforation Process (Halliburton2012)

\subsection{Perforating Objective}

In the early days, perforating was performed with a bullet gun. Today the bullet gun has been almost completely replaced with the shaped-charge perforator. The shaped charge consists of a case or container, the main explosive material, and a liner. The primary objective of a perforating gun is to provide effective flow communication between a cased wellbore and a productive 
reservoir. To achieve this, the perforating gun "punches" a pattern of perforations through the casing and cement sheath and into the productive formation.

\subsubsection{Perforating Gun shapes}

To create a perforation, a perforating gun is used to "shoot" a hole through the casing and cement. Over $90 \%$ of wells are perforated using a shaped charge perforating system. The shaped charge has essentially replaced the bullet gun, which was the main perforating tool prior to World War II. Shaped charge is made of 5 components (Figure 6 and Figure 7):

Main explosive charge

- Cavity covered with a cone shaped metal liner

- Primer charge (fuse)

- Detonating cord

- Case

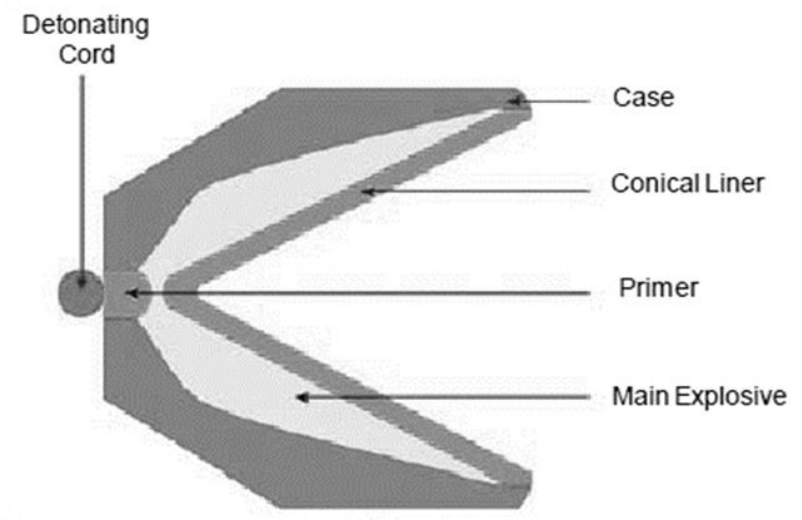

Figure 6: Shaped charge components (www.devonenergy.com)

Fig. 7 shows the schematic of a gun system with shaped charges, which shows the main components of the system and the detonation sequence. The energy resulting from the detonation is directed by the conical case. The charge liner plays an important role, since this is the part which collapses and emerges at a high velocity, creating a jet of metal particles. 


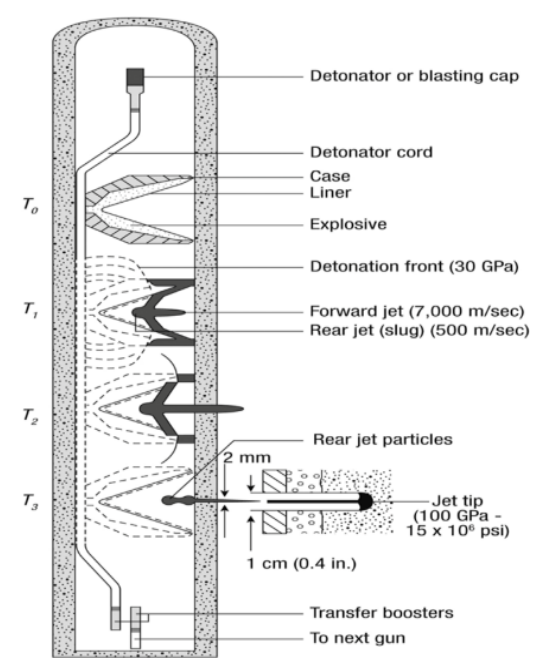

Figure 7: Perforating gun and detonation sequence (Economides et al. 1994).

\subsubsection{Type of gun}

All perforating guns can be classified into three broad categories:

- Expendable gun

- Semi-expendable gun

- Retrievable hollow carrier gun

\subsubsection{Expendable gun}

All parts of the gun below the collar locator are either destroyed during the perforation explosion or left in the well as debris. Expendable gun is used in shallow wells and usually cost less than other types of guns. It is used where wellbore restrictions allow only limited access, as in throughtubing applications. Expendable guns allow the use of larger jet charges; however, the guns can cause casing damage.

\subsubsection{Semi-expendable}

A semi-expendable gun has a metal bar that holds the shaped charges. After firing, some of the gun disintegrates, part of the jet charges fall to the bottom of the hole, and the metal bar is recovered. The semi-expendable gun costs slightly more than an expendable gun with comparable shot density. Like the expendable gun, the semi-expendable gun can use larger jet charges than the hollow carrier guns, and the possibility of casing damage exists.

\subsubsection{A retrievable gun}

It is retrievable from the wellbore after firing; there is minimum distortion of the gun body to help ensure easy retrieval. A retrievable hollow carrier gun is the most widely used gun because it 
- Is highly reliable

- Is mechanically rugged and strong

- Can be used in high temperature and pressure environments

- Leaves no (or minimal) debris in the hole

- Eliminates casing damage

- Offers high charge performance the hollow carrier gun contains all parts inside a steel tube that is resistant to wellbore fluids. When the gun is fired, most debris remains inside the tube and is retrieved at the surface.

Figure 8 shows four different perforating guns from Schlumberger.

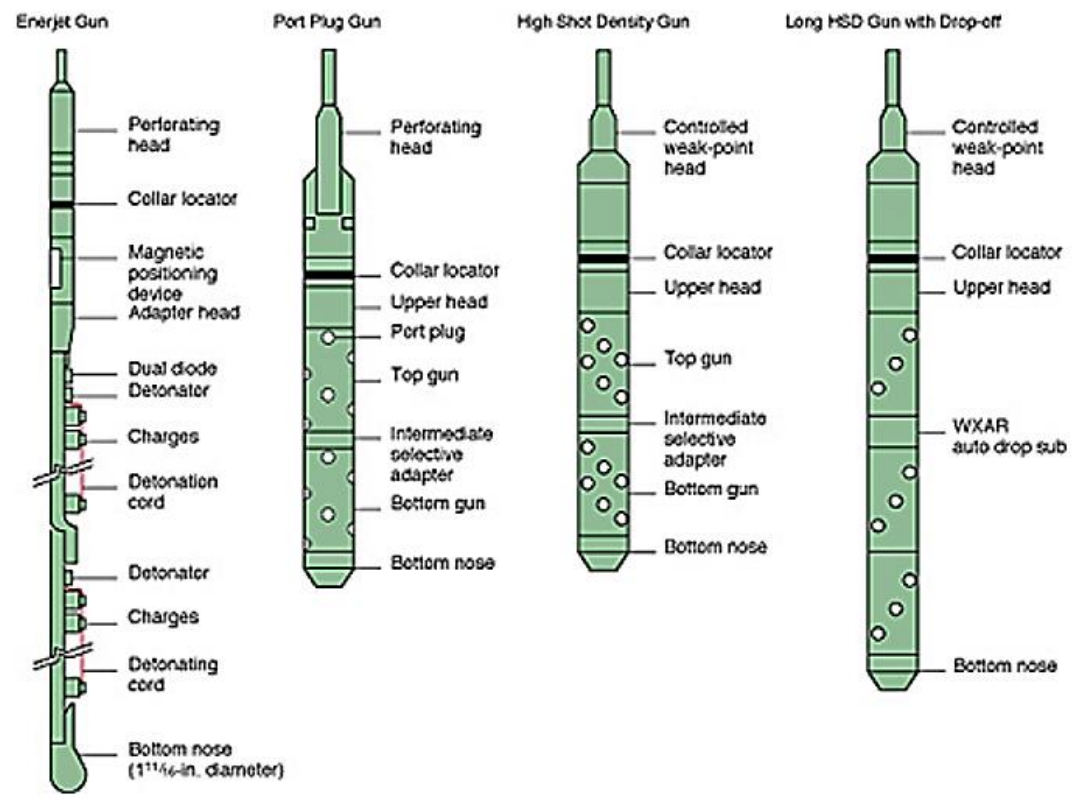

Figure 8: Schlumberger's four perforating guns

\subsection{Perforation geometry}

Perforating is the only way to establish conductive tunnels that link oil and gas reservoirs to steel-cased wellbore which lead to surface (Figure 9). However, perforating also damages formation permeability around perforation tunnels. This damage and perforation parametersformation penetration, hole size, number of shots and the angle between holes-have a significant impact on pressure drop near a well and, therefore, on production. Optimizing these parameters and mitigating induced damage are important aspect of perforation. 


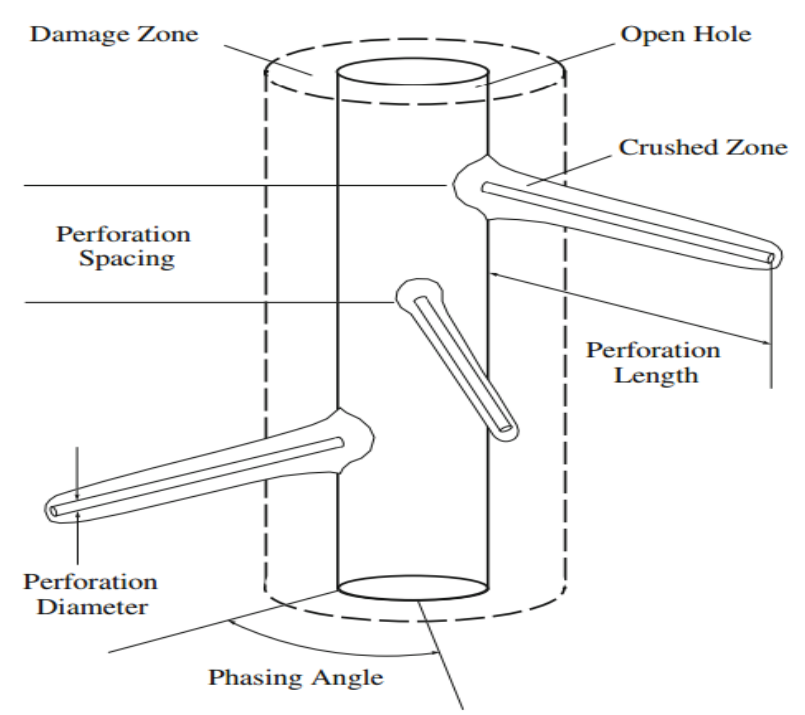

Figure 9: Perforation spacing and geometry (Economides et al. 1994).

\subsection{Shot density}

It is the measurement of the perforations made per unit length of the gun. It is given by shots per meter or foot (spm/spf). The density usually depends upon the production requirements and formation characteristics. However, high shot density and $60^{\circ}$ phasing is a common perforating mechanism for high perm formations but this is probably the worst thing to do in low strength sandstones (leads to extensive shock damage).

\subsection{Phasing}

Reason for phasing is to improve contact angle with the formation for the completion or stimulation design. Gun phasing may also help reduce sand failures in soft sand formations. Common phasing are $0^{\circ}, 180^{\circ}, 120^{\circ}, 90^{\circ}$ and $60^{\circ}$ with varying linear distance between the charges along the gun body (Figure 10).

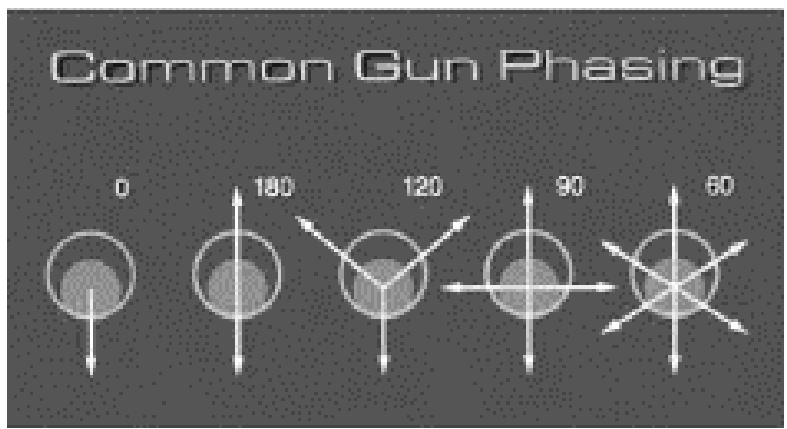

Figure 10: Common gun phasing used for perforation operations (King, 2007) 
Selection of phasing depends on many factors:

- $60^{\circ}, 90^{\circ}, 120^{\circ}$ phasing for fracturing. They are preferred because they have the ability to perforate at different angles, utilizing the surrounding reservoir body. They are usually used with guns having high outer diameter, due to which centralization of the gun is not required.

- $60^{\circ}$ for gravel packing.

- $0^{\circ}$ for through-tubing perf addition (common).

- $180^{\circ}$ for orienting perf guns to known fracture direction. Gun phasing may also help reduce sand failures in soft sand formations.

All perforation flow patterns are utilized. 90 phasing which provides the best radial depletion can be very effective when conducted with high shot densities. However, the selection of phasing will depend not only on shot densities but gun size, gun clearance, formation isotropy or anisotropy with respect to permeability.

\subsection{Perforation Diameter}

Perforation diameter may influence the productivity ratio, especially in high productivity wells. Perforation diameter is dependent on: (1) charge design and (2) the clearance of the gun in the casing.

The choice between penetration length and entrance hole size is made available by the size of the charges and an element of the charge design. A charge's design affects the hole diameter and penetration. For completion in weak formations in which sand production could be an issue and gravel packing or frac-packing will not be used, rather deep penetrating charges at high density of about 12 to 16 SPF (39 to 54 SPM) are recommended.

A according to the study by Locke (1981), increasing the perforation diameter above 0.25 in., gives a minute increase in the productivity ratio. He also managed, by using Fanning Equation, to estimate the optimum perforation diameter by knowing the expected flow rate.

Gravel pack charges produce large diameter holes (around 1- inch), while the deep penetrating charges will produce an opening between 0.5 and 0.75 inches in diameter.

\subsection{Clean-Up}

Once the jet pierces the casing and cement, the portion of formation immediately surrounding the blast will be compacted and filled with debris (Figure 11). This material must be removed in order for production to be restored to its maximum capacity. The formation (generally quartz) and cementing agents (generally calcite or quartz) are crystalline in nature, and will tend to form an impermeable sheath around the circumference of the blast zone. In addition, the blast tends 
to create debris within the perforation. The debris can be pieces of the formation and cement, metal from the casing and shaped charge housing, and pieces of the shaped charge itself.

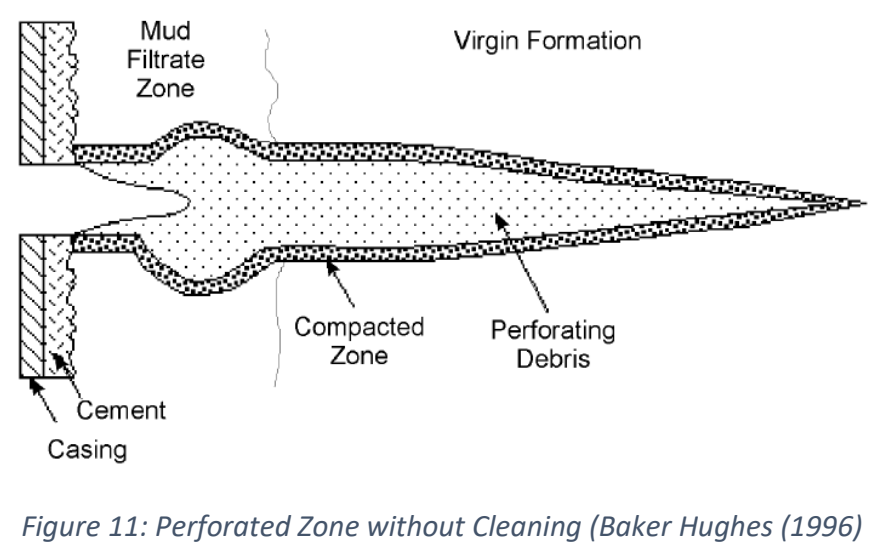

The crushed material and compacted zone can be removed by immediately placing the formation in an under balanced situation, which allows the debris material to be flushed into the well bore and removed at the surface. If the formation contains sufficient carbonate material, it can be acidized. However, quartz and metal require powerful acids to dissolve them. Once the perforations are cleaned, they must remain open (not be plugged) or filled with a material that is both porous and permeable (packed with sand). This will allow the flow of hydrocarbons through the perforations and into the borehole (Figure 12).

\subsection{Sand Control}

During hydrocarbon production from unconsolidated sand reservoirs, there is a tendency for the sands to compact after the pore fluids are removed. When the reservoir fluids are produced, pressure differential and frictional drag forces are created which can exceed this compaction matrix strength, and a significant amount of the sand can be "produced" (i.e. flow into the borehole and production tubing). This sand production is very detrimental to the well causing erosion of downhole and surface equipment, filling up surface separators and storage tanks, sand-laden fluids and increased costs for sand disposal

\subsection{Wellbore Pressure during Perforations}

The pressure differential between a well bore and the reservoir prior to perforation can be described as underbalanced, balanced or over-balanced. A desirable underbalance condition exists when hydrostatic pressure inside the well casing is less than pressure in the formation. 


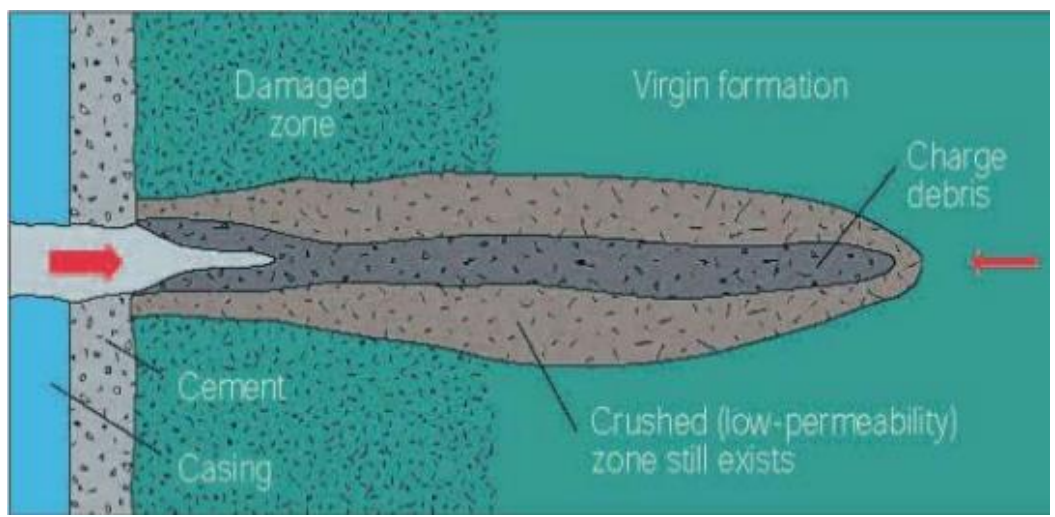

Figure 12: Perforation immediately after creation (Bellarby (2009))

\subsubsection{Overbalanced Perforating (Pwellbore > Preservoir)}

The primary concern is the selection of clean (and in some cases acidic) fluid in the wellbore to ensure minimal perforation plugging. The higher wellbore pressure ensures that no reservoir fluid flows to the well (Figure 13).

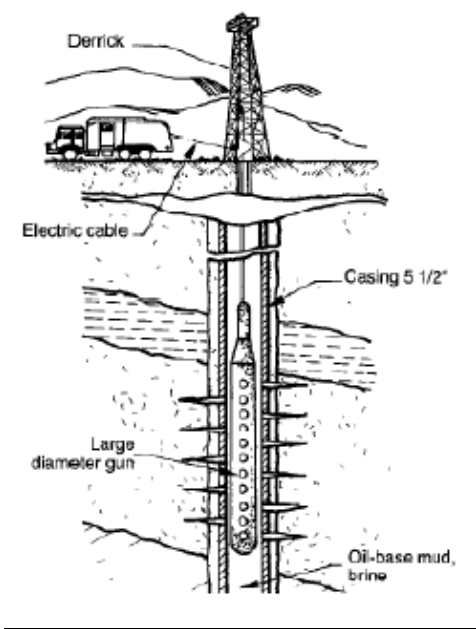

Figure 13: Overbalance perforating Casing Gun (Economides et al. 1994).

\subsubsection{Underbalanced Perforating ( Pwellbore $_{\text {Preservoir }}$ )}

In underbalance perforation the wellbore pressure, before perforation, is kept less than the formation reservoir pressure. To perforate underbalanced, the wellhead should be installed with a 
pressure-tested lubricator on it. It is known to be one of the best methods for creating open, undamaged perforations in which the permeability is high enough to create sufficient flow rate in order to break the crush zone loose and carry it out of the perforation tunnel; however, the guns are small in diameter compared to casing since they must pass through the tube; the penetration is thus shallower; small diameter retrievable carriers can be used. The advantage of underbalanced perforating is that the amount of shrapnel and other materials entering the reservoir is minimized (Figure 14).

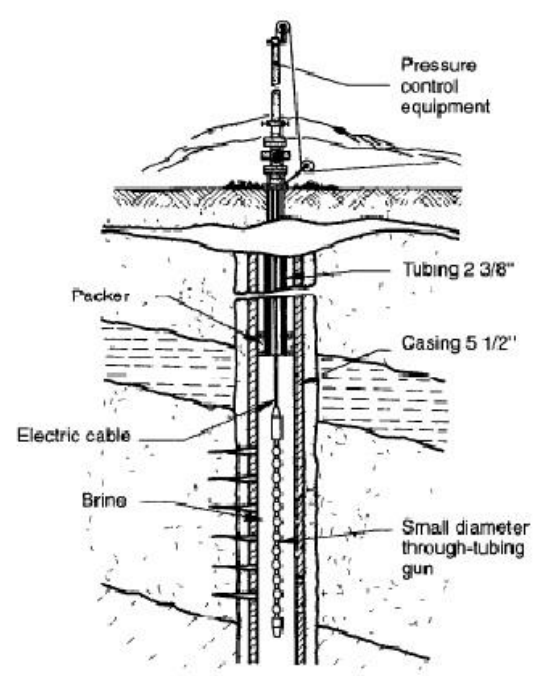

Figure 14: Underbalanced perforating Casing Gun (Economides et al. 1994).

To "kill the well" the wellbore must be filled with heavy fluids to hold back the well's natural pressure. No matter how well that fluid is balanced, some inevitably flows into the reservoir rock. Even when the wells are treated and flowed back to surface until only well fluids appear to be coming out of the well, chemicals and materials used to lend weight to the kill fluids are left behind in the reservoir, plugging flow paths and hindering the well's ability to flow. One answer to the damage of kill fluids is not to use them, particularly in highly permeable reservoirs where they flow easily and deeply into the producing formation. For years, companies have been drilling underbalanced, that is allowing the formations controlled flow even as they are being drilled. Now, to eliminate heavy kill fluids, perforating companies are doing the same thing and shooting the wells underbalanced (Figure 15). 

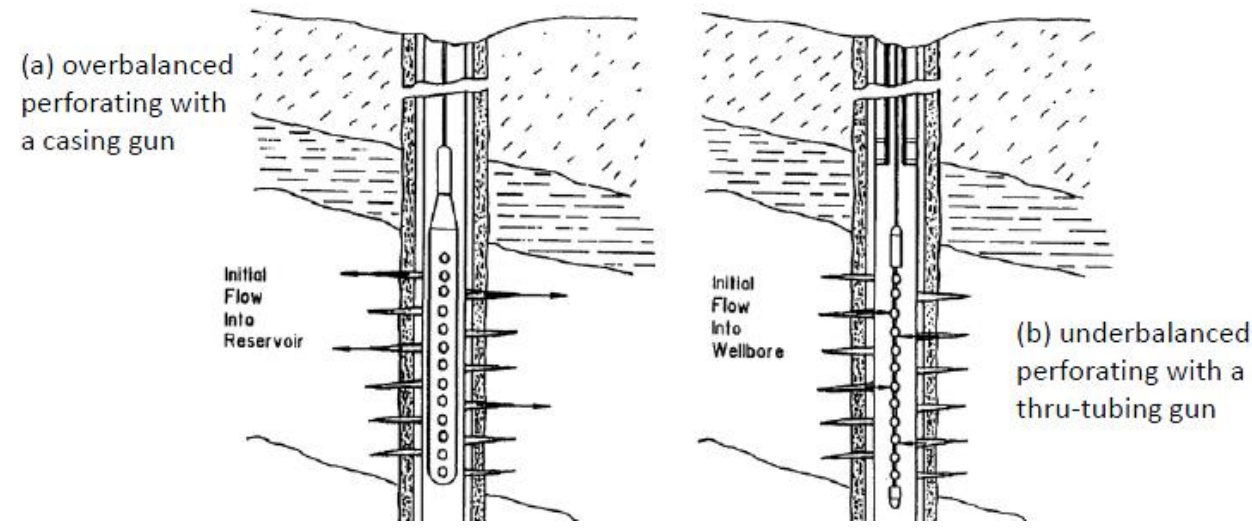

Figure 15: Overbalance/Underbalance Perforation (Economides et al. 1994). 


\section{CHAPTER 4}

\section{Formulation and Discussions}

Damaged zone is caused by drilling fluids, the crushed zone surrounding the perforation tunnel, casing pipe, and the cement behind the pipe. The damage around a wellbore can be represented by a skin factor. This skin which is referred to as laminar skin, occurs because of near well bore damage to the formation or limited entry and is constant for all flow rates.

Laminar skin $S=S_{p f}+S_{d}+S_{c z}+S_{p p}+S_{\theta}$

\subsection{Calculation of Perforation Skin $\left(S_{p f}\right)$}

Karakas and Tariq (1991) presented a semi analytical solution for estimation of the perforation skin effect. Perforations, depending upon their short density, offer flow restrictions to the wellbore, resulting in a reduced production rate. Loss of productivity due to perforations can also be expressed as a skin factor Sp and depends upon perforation geometry and perforation quality. Figure 16 illustrates some parameters used in this model.

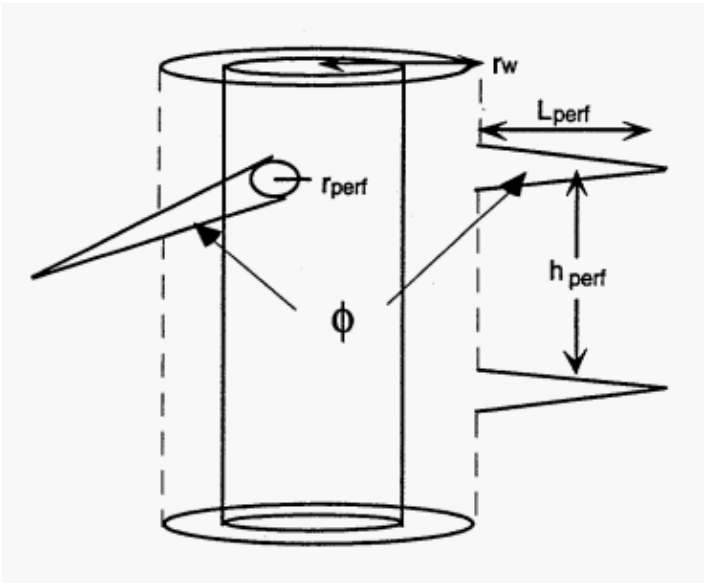

Figure 16: Perforation Skin Calculation (Economides et al. 1994).

Using a three-dimensional finite-element model, they formulated the dependency of perforation skin on the angular perforation phasing, the perforation length and the well radius. The total perforation skin effect is then:

$$
S_{p f}=S_{H}+S_{V}+S_{w b}
$$

where

$S_{H}=$ Plane flow effect

$S_{V}=$ Vertical skin effect 
$S_{w b}=$ Wellbore effects

4.1.1 Calculation of $S_{H}$

$S_{H}=\ln \left(\frac{r_{w}}{r^{\prime}(\emptyset)}\right)$

Where $r_{w}^{\prime}(\theta)$ is the effective wellbore radius and is a function of the phasing Angle $(\theta)$ :

$$
\begin{array}{ll}
r_{w}^{\prime}(\theta)=\left\{a_{\theta}\left(r_{w}+L_{\text {Perf }}\right)\right\} & \text { for } \theta \neq 0 \\
r_{w}^{\prime}(\theta)=\left\{a_{\theta}\left(r_{w}+\frac{L_{\text {Perf }}}{4}\right)\right\} & \text { for } \theta=0
\end{array}
$$

The constant $\left(a_{\theta}\right)$ depends on the perforation phasing and can be obtained from Table1. The numerical values for ' $a_{\theta}$ ' were obtained by the authors (Karakas and Tariq (1999)) using finiteelements simulations.

This skin effect $\left(\boldsymbol{S}_{\boldsymbol{H}}\right)$ is negative (except for $a_{\theta}=0$ ), but its total contribution is usually small.

\subsubsection{Calculation of $S_{V}$ :}

$$
s_{V}=10^{a} h_{D}^{b-1} r_{D}^{b}
$$

Where $h_{D}$ and $r_{D}$ are defined by:

$$
\begin{aligned}
h_{D} & =\frac{h_{P}}{L_{P}} \sqrt{\frac{k_{H}}{k_{V}}} \ldots \ldots \ldots \ldots . . . \\
r_{D} & =\frac{r_{P}}{2 h_{P}}\left(1+\sqrt{\frac{k_{V}}{k_{H}}}\right)
\end{aligned}
$$

$$
a=a_{1} \log r_{D}+a_{2}
$$

$$
b=b_{1} r_{D}+b_{2}
$$

The constants $a_{1}, a_{2}, b_{1}$ and $b_{2}$, are functions of the perforation phasing and can be obtained from Table 1. For large values of $h_{\text {perf }}$ (less number of shots per foot), ' $S_{V}$ ' can be large. ' $S_{V}$ 'values can be minimized with deep penetrating perforators and or high shot density perforating guns. 
Table 1: Constants for perforation skin effect calculation

\begin{tabular}{|c|c|c|c|c|c|c|c|}
\hline $\begin{array}{c}\text { Perforation } \\
\text { Phasing }\end{array}$ & a & a1 & a2 & b1 & b2 & c1 & c2 \\
\hline $0(360)$ & 0.25 & -2.091 & 0.0453 & 5.1313 & 1.8672 & $1.6 \mathrm{E}-01$ & 2.675 \\
\hline 180 & 0.5 & -2.025 & 0.0943 & 3.0373 & 1.8115 & $2.6 \mathrm{E}-02$ & 4.532 \\
\hline 120 & 0.648 & -2.018 & 0.0634 & 1.6136 & 1.777 & $6.6 \mathrm{E}-03$ & 5.32 \\
\hline 90 & 0.726 & -1.905 & 0.1038 & 1.5674 & 1.6935 & $1.9 \mathrm{E}-03$ & 6.155 \\
\hline 60 & 0.813 & -1.898 & 0.1023 & 1.3654 & 1.649 & $3.0 \mathrm{E}-04$ & 7.509 \\
\hline 45 & 0.86 & -1.788 & 0.2398 & 1.1915 & 1.6392 & $4.6 \mathrm{E}-05$ & 8.791 \\
\hline
\end{tabular}

\subsubsection{Calculation of $S_{W b}$ :}

The skin due to the wellbore effect is given as

$$
s_{W b}=c_{1} e^{c_{2} r W D}
$$

Where

$$
r_{W D}=\frac{r_{w}}{L_{P}+r_{w}}
$$

The constants $C_{1}$ and $C_{2}$ also can be obtained from Table1. These constants are obtained from numerical simulations. The skin ' $S_{w b}$ ' was found to be significantly larger for $0^{0}$ phasing than the multi-directional phasing.

\subsection{Calculation of Damage Zone Skin $\left(\mathrm{S}_{\mathrm{d}}\right)$}

Due to the flow of drilling mud into the formation, the permeability around the wellbore is reduced. The terms $K_{d}$ and $r_{d}$ represent the permeability and the radius of this damaged zone, respectively. If the well is completed along the entire length of the formation, then the Hawkin's formula can be used to calculate the resulting skin.

$S_{d}=\left(\frac{k}{k_{d}}-1\right) \ln \frac{r_{d}}{r_{w}}$

If the well is completed only partially then Jones et al. suggested that Hawkin's formula can no longer be used since the flow into the well is no longer radial. Based upon the results from their numerical model they presented an adaptation of Hawkin's formula that can be used as follows when the well is partially completed: 
$S_{d}=\frac{h}{h_{p}}\left[1-0.2 \frac{\left(r_{d}-r_{w}\right)}{h_{p}}\right]\left(\frac{k}{k_{d}}-1\right) \ln \frac{r_{d}}{r_{w}}$

$\left(h_{p}\right)$ is the length of the perforated interval. This result theoretically applies only when $\left(h_{p}\right)$ is small compared with ( $\mathrm{h}$ ) (total bed thickness) and when the perforated interval is in the center of the productive zone. But the authors suggested that for most cases of practical interest these restrictions can be ignored.

\subsection{Calculation of Crushed Zone Skin $\left(\boldsymbol{S}_{c z}\right)$ :}

The crushed zone around each perforation has a thickness of about 0.5 inches. The Permeability of this zone can be smaller or larger than the near-wellbore permeability, depending on whether compaction or collapse occurs. The equation for laminar skin through the crushed zone can be derived from the radial flow equations and is given as:

$S_{c z}=\frac{h}{L_{p e r f} n_{p}}\left(\ln \frac{r_{c z}}{r_{p}}\right)\left(\frac{k}{k_{c z}}-\frac{k}{k_{d}}\right)$

where

$r_{p}=$ radius of the perforation

$r_{c Z}, k_{c z}=$ radius and permeability of the crushed zone.

When $k_{c z}=k_{d}$ then no additional damage was done due to the crushed particles and hence $\left(S_{c z}\right)$ becomes zero.

\subsection{Calculation of Partial Penetration Skin $\left(S_{p p}\right)$}

A positive skin results from a partially penetrating well. The necessary theoretical development is presented by Nisle and in another paper by Brons et al. This skin is calculated from $S_{p p}=\frac{(1-b)}{b}\left[\ln \left[\frac{\sqrt[h]{\frac{K_{H}}{K_{V}}}}{r_{w}}\right]-G(b)\right]$

Where

$\mathrm{G}(\mathrm{b})=2.948-7.363+11.45 b^{2}-4.675 b^{3}$ 
and (b) is the fractional penetration of the well. Equation (4.14) was determined numerically.

\subsection{Calculation of Well Deviation $\operatorname{Skin}\left(\boldsymbol{S}_{\boldsymbol{\theta}}\right)$ :}

A deviated well gives negative skin. It is due to the increase in the producing-interval area exposed to flow. Cinco et al. developed a pseudo skin factor which gives the difference between the dimensionless pressure created by a slanted well and that created by a vertical well. The calculation of skin factor must be modified because of the difference between the pressure of a slanted well and the pressure of a vertical well. For slant angles from 0 to 75 degrees, and $\frac{h}{r_{w}}>40$, the skin for a deviated well was evaluated as

$S_{\theta}=-\left(\frac{\theta}{41}\right)^{2.06}-\left(\frac{\theta}{56}\right)^{1.865} \log \left(\frac{h_{d}}{100}\right)$

Where

$\theta=\tan ^{-1}\left(\sqrt{\frac{K V}{K H} * \tan \theta}\right)$

And

$h_{d}=\frac{h}{r_{w}} \sqrt{\frac{K_{H}}{K_{V}}}$

\subsection{Non-Darcy Flow}

Non-Darcy flow is typically observed in high-rate gas wells when the flow converging to the wellbore reaches flow velocities exceeding the Reynolds number for laminar or Darcy flow, and results in turbulent flow. The equation for calculating the non-Darcy flow coefficient for gas flow comprises three components: crushed zone, damaged zone, and near-wellbore reservoir rock.

\subsection{Pressure Drop Due to the Gravel Pack}

Wells are usually completed with gravel pack in order to prevent formation loss at the wellbore which causes additional pressure drop to the flow of formation fluids which result of gravel in the perforation tunnel and gravel between the liner and the casing. 


\section{CHAPTER 5}

\section{Results and Discussion}

\subsection{Results}

The skin factors were calculated for various combinations of perforation characteristics and the results are presented in this section. Table 2 summarizes the results of the calculations conducted using Equations 4.7 and 4.8 for constants a and $\mathrm{b}$. The constants $a_{1}, a_{2}, b_{1}$ and $b_{2}$, are functions of the perforation phasing and can be obtained from Table 1 .

\section{Table 2: Calculated $a$ and $b$}

\begin{tabular}{|c|c|c|}
\hline Angle & $\mathbf{a}$ & $\mathbf{b}$ \\
\hline 120 & 1.295962 & 2.042483 \\
\hline 90 & 1.088389 & 1.951382 \\
\hline 60 & 1.089011 & 1.873647 \\
\hline 0 & 1.417982 & 2.711445 \\
\hline
\end{tabular}

Table 3 lists the results of the calculations using set of equations given in Chapter 4 for total perforation skin effect and $r_{w}^{\prime}(\theta)$ which is the effective wellbore radius.

Table 3: Calculated Values

\begin{tabular}{|c|c|c|c|c|c|}
\hline Phasing & $r_{w}^{\prime}(\varnothing)$ & SH & Sv & Swb & SPf \\
\hline 120 & 6.642 & -0.20872 & 0.051364057 & 0.02788 & -0.12947 \\
\hline 90 & 7.4415 & -0.18629 & 0.03116873 & 0.010063 & -0.14506 \\
\hline 60 & 8.33325 & -0.16636 & 0.041121965 & 0.002293 & -0.12294 \\
\hline 0 & 0.6875 & -2.01643 & 0.008913205 & 0.330185 & -1.67733 \\
\hline
\end{tabular}

Calculations were based on the combination of four different values of perforation diameter (1.0, 1.5, 2.0 and 2.5 in.), three values of perforation length (5, 10 and $15 \mathrm{in}$.), and four values of phase angle $(0,60,90$, 120 degrees). Table 4 summarizes the results of perforation skin with different shot phasing, perforation length and radius using a set of equations given earlier in Chapter 4 
Table 4: Skin Factors due to perforations.

\begin{tabular}{|c|c|c|c|c|}
\hline Case & $\begin{array}{c}\text { Shot } \\
\text { Phasing }\end{array}$ & $\begin{array}{c}\text { Length of } \\
\text { Perf }\end{array}$ & $\begin{array}{c}\text { Perf } \\
\text { Radius }\end{array}$ & Perf Skin \\
\hline 1 & 0 & 5 & 1 & 10. 74892 \\
\hline 2 & $\mathrm{O}$ & 5 & 1.5 & 3.1777 \\
\hline 3 & $\mathrm{O}$ & 5 & 2 & 0.277 \\
\hline 4 & $\mathbf{O}$ & 5 & 2.5 & -1.0939 \\
\hline 1 & $\mathrm{O}$ & 10 & 1 & 12.4293 \\
\hline 2 & $\mathrm{O}$ & 10 & 1.5 & 4.85809 \\
\hline 3 & $\mathrm{O}$ & 10 & 2 & 1.957376 \\
\hline 4 & $\mathrm{O}$ & 10 & 2.5 & 0.58642 \\
\hline 1 & $\mathbf{O}$ & 15 & 1 & 13.05941 \\
\hline 2 & $\mathrm{O}$ & 15 & 1.5 & 5.488223 \\
\hline 3 & $\mathrm{O}$ & 15 & 2 & 2.58751 \\
\hline 4 & $\mathrm{O}$ & 15 & 2.5 & 1.216553 \\
\hline 1 & 60 & 5 & 1 & 7.5569 \\
\hline 2 & 60 & 5 & 1.5 & 4.2477 \\
\hline 3 & 60 & 5 & 2 & 2.6035 \\
\hline 4 & 60 & 5 & 2.5 & 1.6543 \\
\hline 1 & 60 & 10 & 1 & 7.7154 \\
\hline 2 & 60 & 10 & 1.5 & 4.4061 \\
\hline 3 & 60 & 10 & 2 & 2.7619 \\
\hline 4 & 60 & 10 & 2.5 & 1.8128 \\
\hline 1 & 60 & 15 & 1 & 7.7699 \\
\hline 2 & 60 & 15 & 1.5 & 4.4607 \\
\hline 3 & 60 & 15 & 2 & 2.8164 \\
\hline 4 & 60 & 15 & 2.5 & 1.8673 \\
\hline 1 & 90 & 5 & 1 & 7.3967 \\
\hline 2 & 90 & 5 & 1.5 & 4.1399 \\
\hline 3 & 90 & 5 & 2 & 2.5245 \\
\hline 4 & 90 & 5 & 2.5 & 1.5948 \\
\hline 1 & 90 & 10 & 1 & 7.5741 \\
\hline 2 & 90 & 10 & 1.5 & 4.3173 \\
\hline 3 & 90 & 10 & 2 & 2.702 \\
\hline 4 & 90 & 10 & 2.5 & 1.7722 \\
\hline 1 & 90 & 15 & 1 & 7.6352 \\
\hline 2 & 90 & 15 & 1.5 & 4.3784 \\
\hline 3 & 90 & 15 & 2 & 2.763 \\
\hline 4 & 90 & 15 & 2.5 & 1.8333 \\
\hline 1 & 120 & 5 & 1 & 11.8940 \\
\hline 2 & 120 & 5 & 1.5 & 6.0055 \\
\hline 3 & 120 & 5 & 2 & 3.4486 \\
\hline 4 & 120 & 5 & 2.5 & 2. 1067 \\
\hline 1 & 120 & 10 & 1 & 12.0928 \\
\hline 2 & 120 & 10 & 1.5 & 6.2042 \\
\hline 3 & 120 & 10 & 2 & 3.6474 \\
\hline 4 & 120 & 10 & 2.5 & 2.3055 \\
\hline 1 & 120 & 15 & 1 & 12.1613 \\
\hline 2 & 120 & 15 & 1.5 & 6.2727 \\
\hline 3 & 120 & 15 & 2 & 3.7158 \\
\hline 4 & 120 & 15 & 2.5 & 2.3739 \\
\hline
\end{tabular}

Perforation length increase assumed to penetrate beyond damaged zone and it was varied at different shot phasing angles.

Results for the impact of perforation radius at a given phase angle are shown in Table 5 and plotted in Figure 17 for the 5-in. penetration length. Except for the zero angle phasing with 2.5 in. 
perforation diameter, all calculated values of skin were positive. The largest skin factor was with the smallest radius of perforation at $120^{\circ}$ phasing.

Table 5: Skin factors for a perforation length of 5 in.

\begin{tabular}{|c|c|c|c|c|}
\hline \multicolumn{5}{|c|}{ Skin Factors with Perforation Length $=5$ in. } \\
\hline Perforation Diameter, in. & \multicolumn{5}{|c|}{ Phase Angle, degrees } \\
\hline & 0 & 60 & 90 & 120 \\
\hline 1 & 10.7489 & 7.5569 & 7.3967 & 11.894 \\
\hline 1.5 & 3.1777 & 4.2477 & 4.1399 & 6.0055 \\
\hline 2 & 0.277 & 2.6035 & 2.5245 & 3.4486 \\
\hline 2.5 & -1.0939 & 1.6543 & 1.5948 & 2.1067 \\
\hline
\end{tabular}

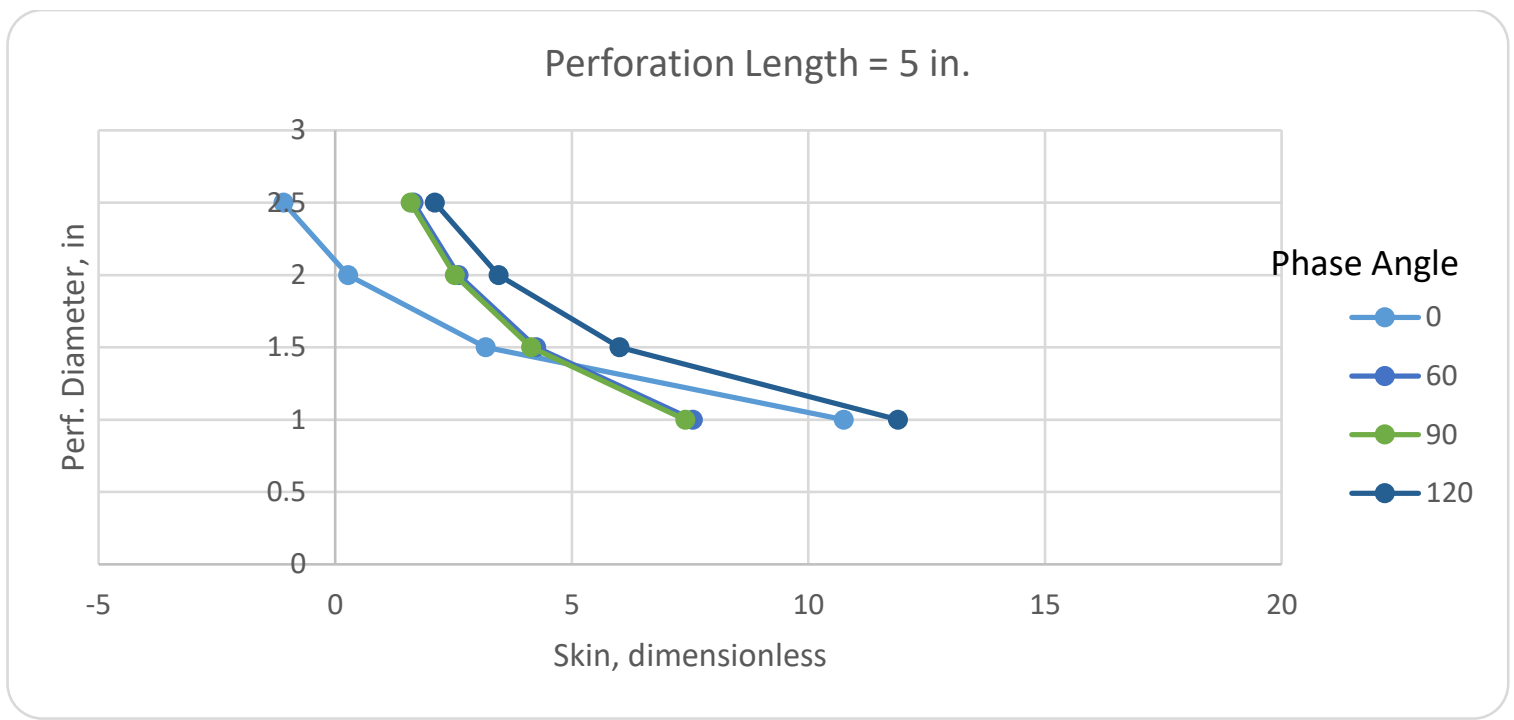

Figure 17: Variation of skin factor with 5-in. perforation length.

Table 6 lists the changes in skin factors due to perforation diameter and phase angle for the 10-in. penetration length. The results are also plotted in Figure 18. All calculated skin values were positive with 1-in. perforation diameters yielding the largest skin values.

Table 6: Skin factors for a perforation length of $10 \mathrm{in.}$

\begin{tabular}{|c|c|c|c|c|}
\hline \multicolumn{5}{|c|}{ Skin Factors with Perforation Length $=10$ in. } \\
\hline Perforation Diameter, in. & \multicolumn{4}{c|}{ Phase Angle, degrees } \\
\hline 1 & 0 & 60 & 90 & 120 \\
\hline 1.5 & 12.4293 & 7.7154 & 7.5741 & 12.0928 \\
\hline 2 & 4.8580895 & 4.4061 & 4.3173 & 6.2042 \\
\hline 2.5 & 1.9573763 & 2.7619 & 2.702 & 3.6474 \\
\hline & 0.5864196 & 1.8128 & 1.7722 & 2.3055 \\
\hline
\end{tabular}




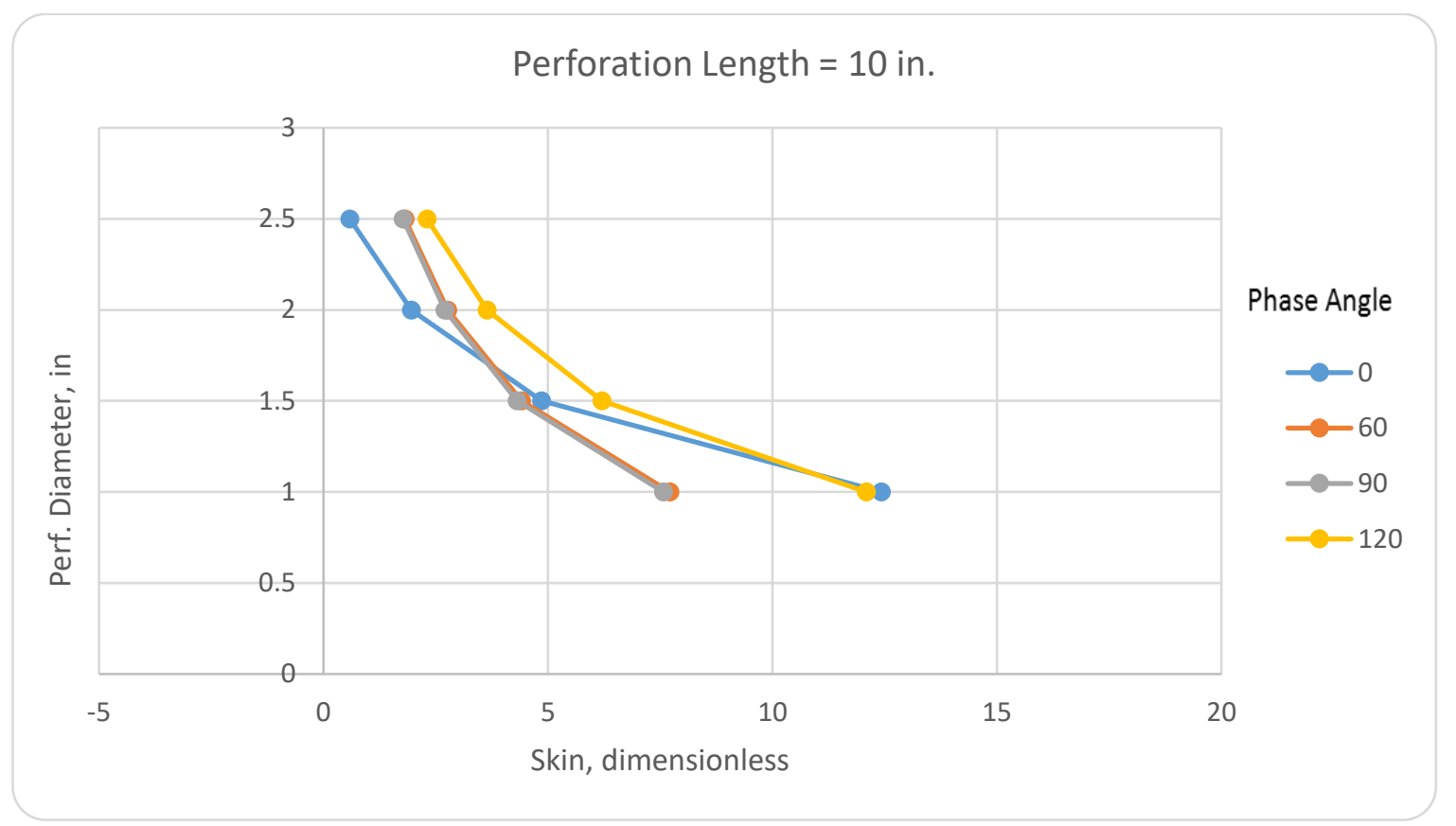

Figure 18: Variation of skin factor with 10-in. perforation length.

Results for the impact of perforation radius at a given phase angle are shown in Table 7 and plotted in Figure 19 for the 15-in. penetration length. All skin values were positive with 1.0 inch perforation diameter exhibiting the largest damage.

Table 7: Skin factors for a perforation length of $15 \mathrm{in.}$

\begin{tabular}{|c|c|c|c|c|}
\hline \multicolumn{5}{|c|}{ Skin Factors with Perforation Length $=15$ in. } \\
\hline Perforation Diameter, in. & \multicolumn{4}{c|}{ Phase Angle, degrees } \\
\hline & 0 & 60 & 90 & 120 \\
\hline 1 & 13.05941 & 7.7699 & 7.6352 & 12.1613 \\
\hline 1.5 & 5.4882233 & 4.4607 & 4.3784 & 6.2727 \\
\hline 2 & 2.5875101 & 2.8164 & 2.763 & 3.7158 \\
\hline 2.5 & 1.2165534 & 1.8673 & 1.8333 & 2.3739 \\
\hline
\end{tabular}

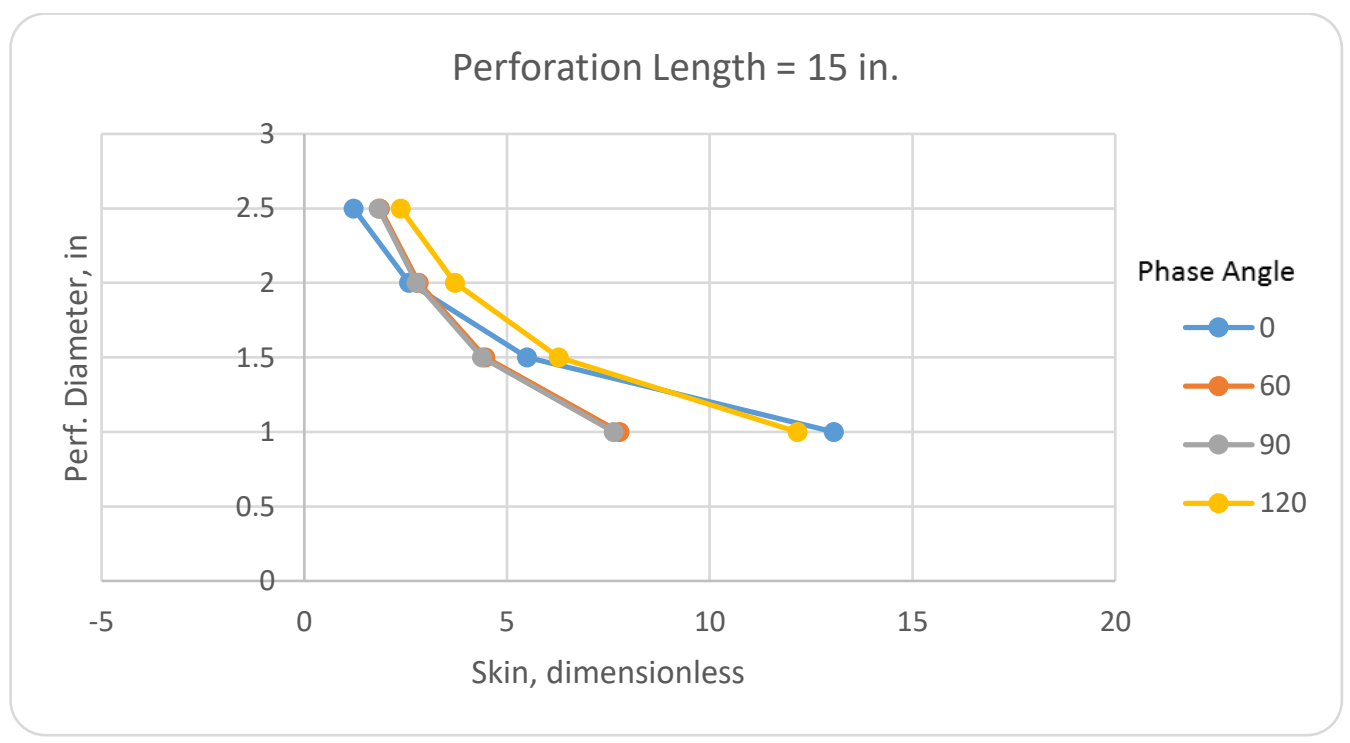

Figure 19: Variation of skin factor with 15-in. perforation length. 
Table 8 lists the changes in skin factors due to perforation length and phase angle for the 1.0-in. perforation diameter. The results are also plotted in Figure 20. The calculated skin values were similar for a given phase angle regardless of the perforation length. diameters yielding the largest skin values.

Table 8: Skin factors for a perforation diameter of 1.0-in.

\begin{tabular}{|c|c|c|c|c|}
\hline \multicolumn{4}{|c|}{ Skin Factors with Perforation Diameter $=1.0$ in. } & \\
\hline Perforation Length, in. & \multicolumn{4}{|c|}{ Phase Angle, degrees } \\
\hline & 0 & 60 & 90 & 120 \\
\hline 5 & 10.74891647 & 7.5569 & 7.3967 & 11.8940 \\
\hline 10 & 12.4293 & 7.7154 & 7.5741 & 12.0928 \\
\hline 15 & 13.05941 & 7.7699 & 7.6352 & 12.1613 \\
\hline
\end{tabular}

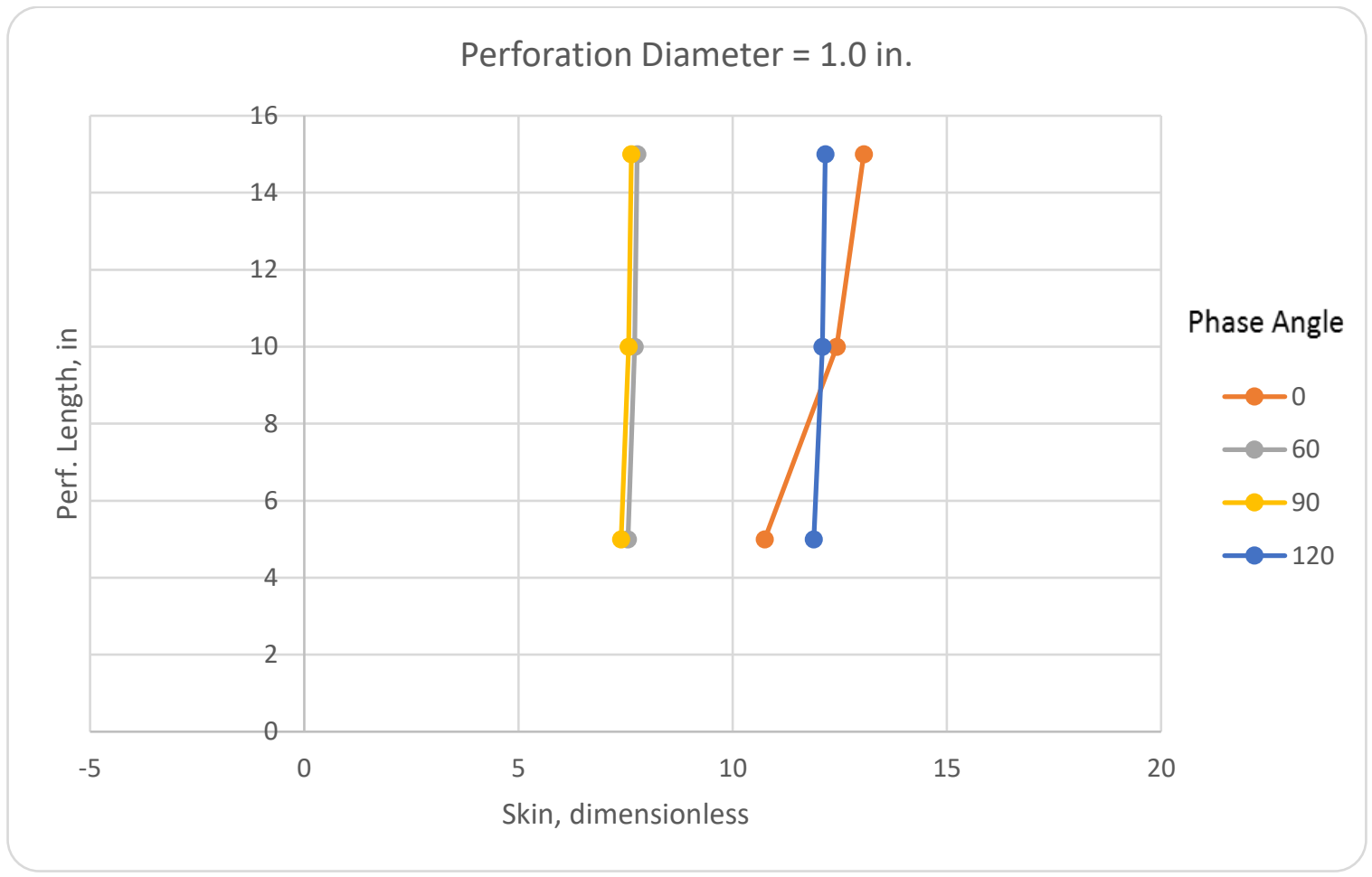

Figure 20: Variation of skin factor with 1.0-in. perforation diameter.

The changes in skin factors due to perforation length and phase angle for 1.5, 2.0, and 2.5-in. perforation diameters are given in Tables 9, 10, and 11. The results are also plotted in Figure 21, 22 , and 23 .

Table 9: Skin factors for a perforation diameter of 1.5-in

\begin{tabular}{|c|c|c|c|c|}
\hline \multicolumn{4}{|c|}{ Skin Factors with Perforation Diameter $=1.5$ in. } & \\
\hline Perforation Length, in. & & se Angle & egrees & \\
\hline & 0 & 60 & 90 & 120 \\
\hline 5 & 3.1777 & 4.2477 & 4.1399 & 6.0055 \\
\hline 10 & 4.8580895 & 4.4061 & 4.3173 & 6.2042 \\
\hline 15 & 5.4882233 & 4.4607 & 4.3784 & 6.2727 \\
\hline
\end{tabular}




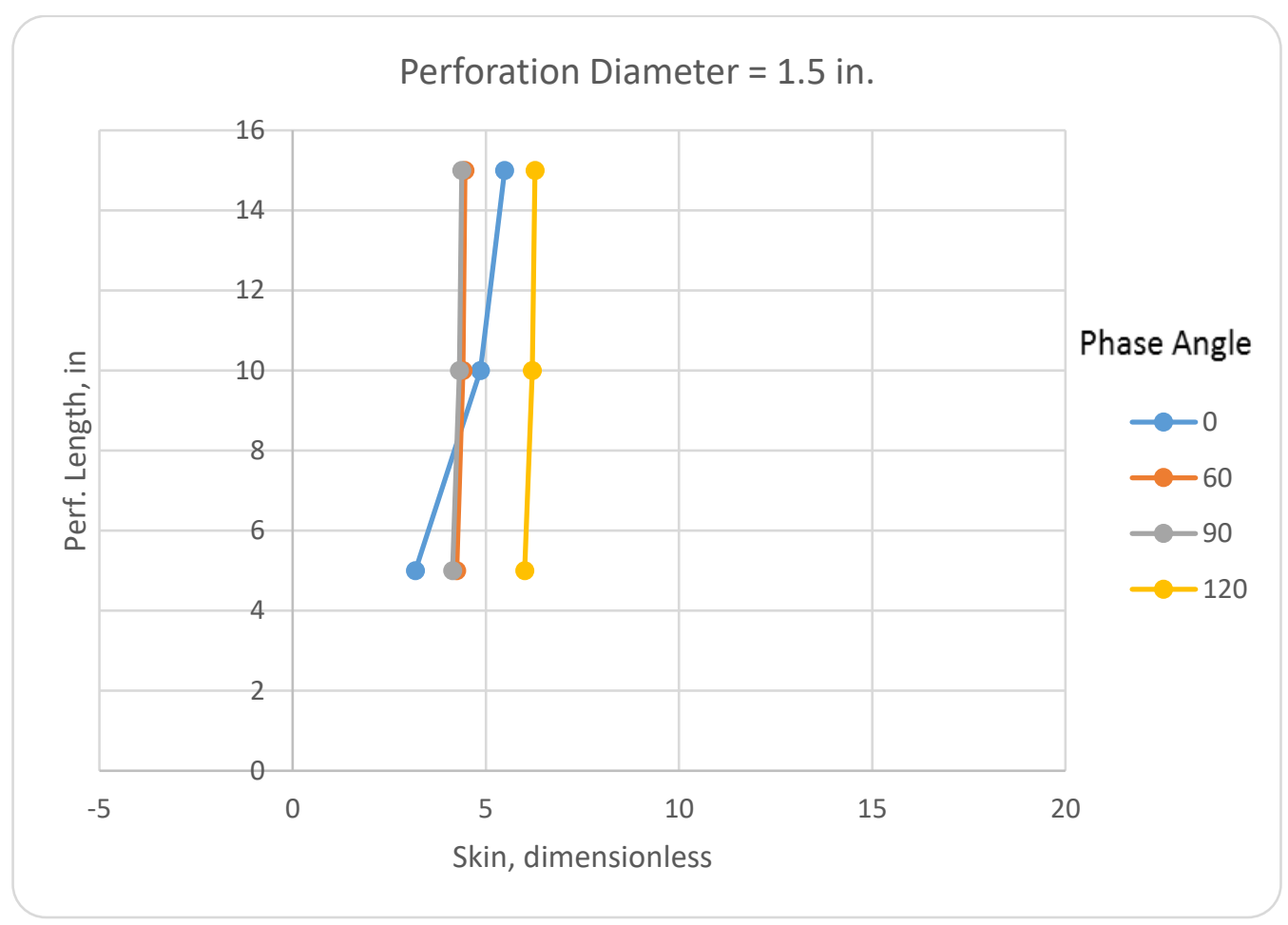

Figure 21: Variation of skin factor with 1.5-in. perforation diameter.

Table 10: Skin factors for a perforation diameter of 2.0-in

\begin{tabular}{|c|c|c|c|c|}
\hline \multicolumn{4}{|c|}{ Skin Factors with Perforation Diameter $=2.0$ in. } & \\
\hline Perforation Length, in. & \multicolumn{3}{|c|}{ Phase Angle, degrees } \\
\hline & 0 & 60 & 90 & 120 \\
\hline 5 & 0.277 & 2.6035 & 2.5245 & 3.4486 \\
\hline 10 & 1.9573763 & 2.7619 & 2.702 & 3.6474 \\
\hline 15 & 2.5875101 & 2.8164 & 2.763 & 3.7158 \\
\hline
\end{tabular}




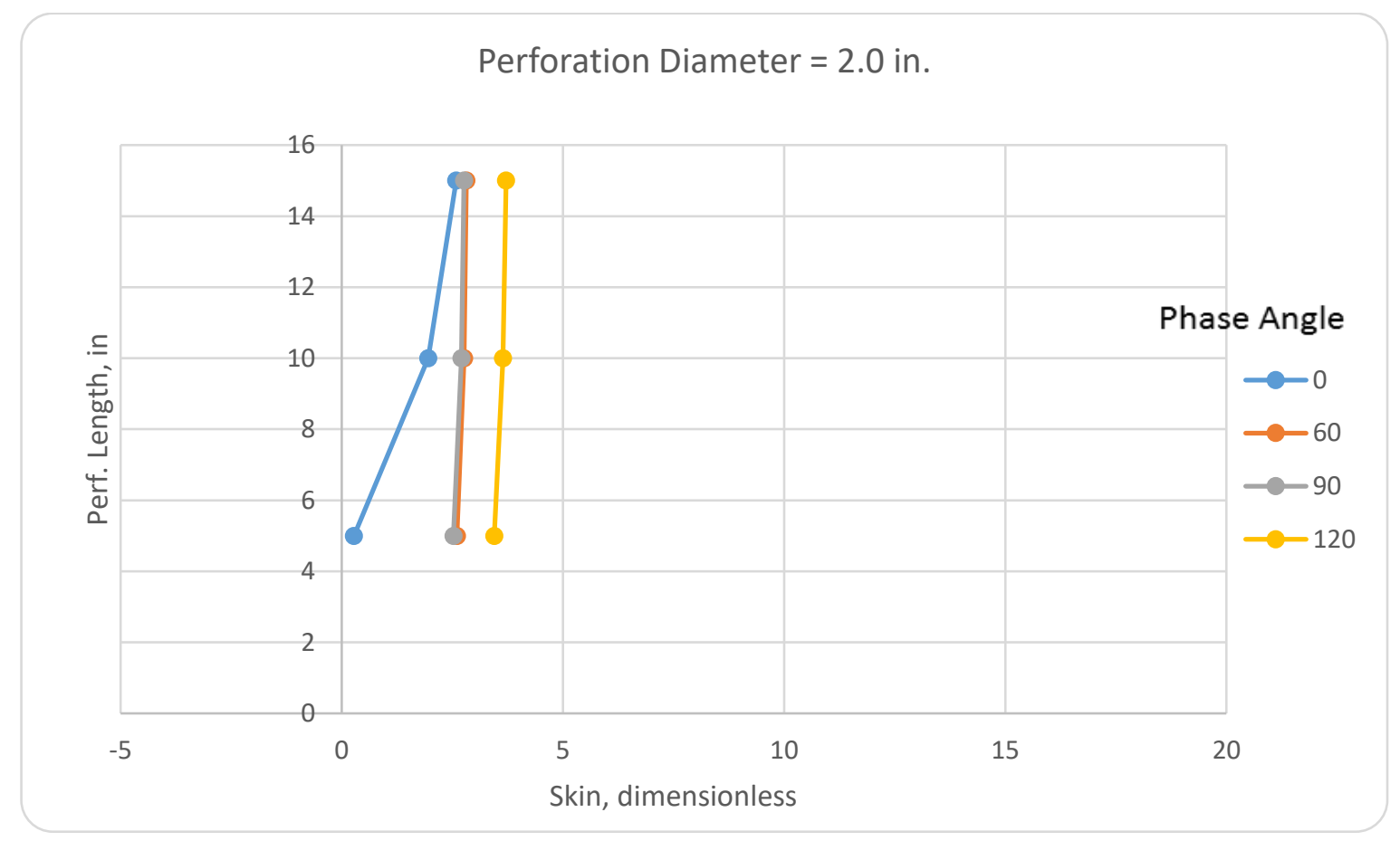

Figure 22: Variation of skin factor with 2.0-in. perforation diameter.

Table 11: Skin factors for a perforation diameter of 2.5-in

Skin Factors with Perforation Diameter $=2.5$ in.

\begin{tabular}{|c|c|c|c|c|}
\hline Perforation Length, in. & \multicolumn{3}{|c|}{ Phase Angle, degrees } \\
\hline & 0 & 60 & 90 & 120 \\
\hline 5 & -1.0939 & 1.6543 & 1.5948 & 2.1067 \\
\hline 10 & 0.5864196 & 1.8128 & 1.7722 & 2.3055 \\
\hline 15 & 1.2165534 & 1.8673 & 1.8333 & 2.3739 \\
\hline
\end{tabular}




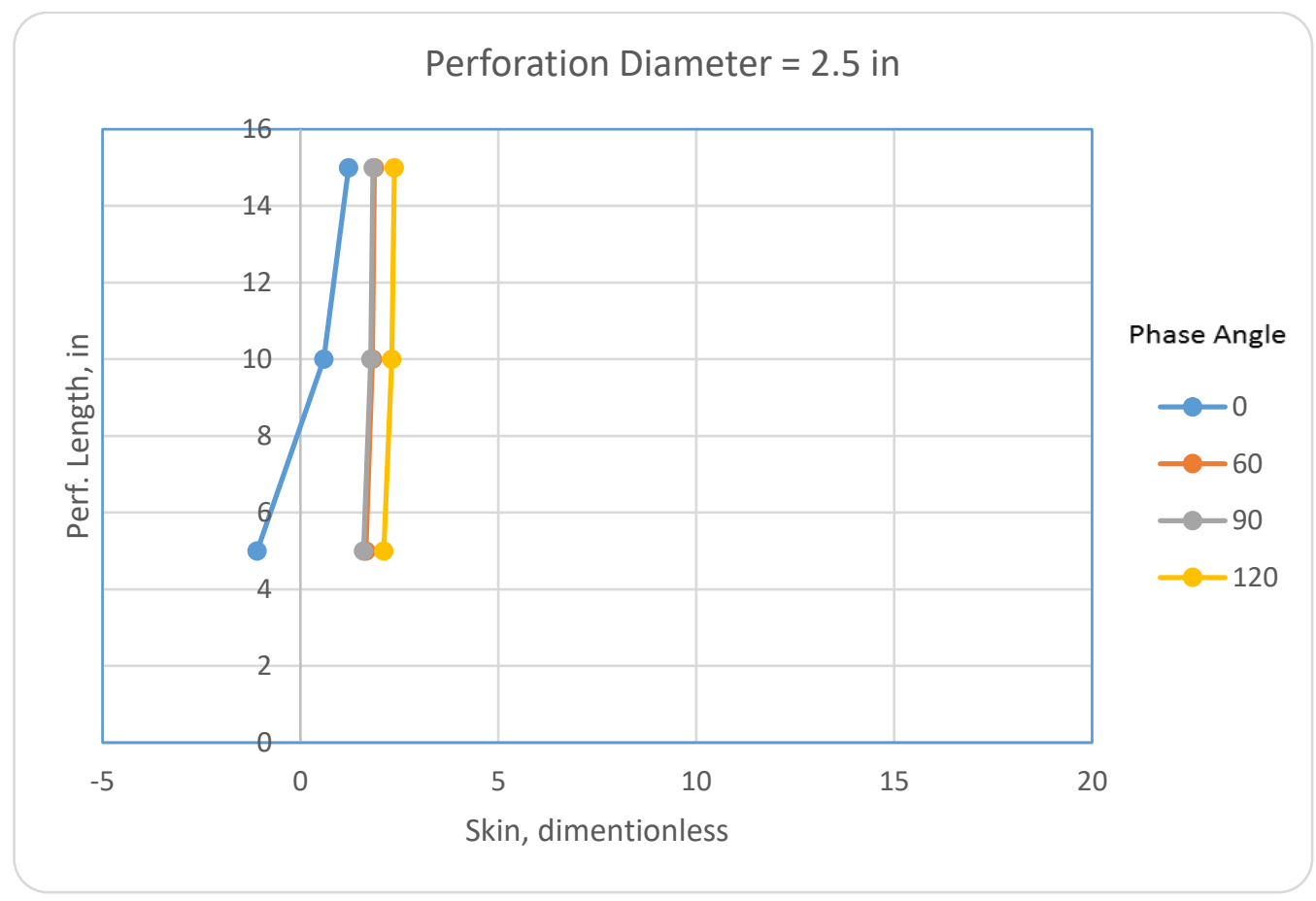

Figure 23: Variation of skin factor with 2.5-in. perforation diameter.

The calculated skin values were similar for a given phase angle regardless of the perforation length. However, the magnitude of the calculated skin factors decreased as the diameter of perforations increased.

\subsection{Discussion}

Controllable factors such as shot density, radius or diameter of perforation, length or depth of perforation and shot phasing or angular distribution of shots were verified to get a zero or negative skin using the Microsoft Excel worksheet so as to increase productivity. Graphs were prepared to compare all the skin factor values at different shot phasing angles. After all these calculations were completed it turns out that almost all conditions of perforations yield positive skin values.

\subsection{Conclusions}

Based on calculations it is difficult to determine the optimum perforations. Additional evaluations are needed with different formation and perforation properties.

Under the conditions considered with current evaluations, perforation diameter had more significant impact on the value of skin factor than the perforation length. Especially, one inch diameter perforations induce large skin factors and it is advisable to use a perforation diameter of 


\subsection{Recommendation}

The skin profiles used in this study were solely based on theoretical backgrounds. A good characterization of real skin profile from a field case is recommended in order to evaluate the performance of horizontal wells. 


\section{REFERENCES}

Amaefule, J. O., et al. "Reservoir description: a practical synergistic engineering and geological approach based on analysis of core data." SPE Annual Technical Conference and Exhibition. Society of Petroleum Engineers, 1988.

Behrmann, L.A., McDonald, B., Schlumberger Wireline \& Testing: “Underbalance or Extreme Overbalance", SPE 57390, August 1999.

Bellarby, J. (2009). Well completion design (Vol. 56). Elsevier.

Bennion, B. "Formation damage-the impairment of the invisible, by the inevitable and uncontrollable, resulting in an indeterminate reduction of the unquantifiable!." Journal of Canadian Petroleum Technology 38.02 (1999).

Brons, F. and Marting, V. E. "The Effect of Restricted Fluid Entry on Well Productivity, "Preprint of paper 1322-G presented at $34^{\text {th }}$ Annual Fall Meeting at SPE (Oct. 4-7, 1959) in Dallas.

Cino-L., H., Miller, F. G., and Ramey, H. J. Jr. "Unsteady-State Pressure Distribution Crested by a Directionally Drilled Well,” JPT (Nov. 1975) 1392-1400; Trans., AIME, 259.

Civan, F. (2007). Reservoir Formation Damage Fundamentals. Modeling, Assessment and Mitigation, 2.

Economides, Michael J. Hill, A. Daniel. and Economides, Christine E. 1994. Petroleum Frick, T. P., and M. J. Economides. "Horizontal well damage characterization and removal." SPE Production \& Facilities 8.01 (1993): 15-22.

Halliburton Perforating Solutions Manual, Halliburton

Hawkins Jr, Joseph E. "XLIX The Ototoxicity of Kanamycin." Annals of Otology, Rhinology \& Laryngology 68.3 (1959): 698-715.

Hawkins, Murray., Jr. “a Note on the Skin Effect,”, “Trans., AIME (1956)207, 356-57

Karakas, M., \& Tariq, S. M. (1991). Semianalytical Productivity Models for Perforated Completions. SPE Prod Eng 6 (1): 73-82.

Locke, S. (1981). An advanced method for predicting the productivity ratio of a perforated well. Journal of Petroleum Technology, 33(12), 2-481.

Mukherjee, Hemanta, and Michael J. Economides. "A parametric comparison of horizontal and vertical well performance." SPE Formation Evaluation 6.02 (1991): 209-216.

Muskat, Morris. "Effect of permeability stratification in cycling operations." Transactions of the AIME 179.01 (1949): 313-328. 
Nisle, R. G. "The effect of Partial Penetration on Pressure Build-up in Oil Wells,". Trans. AIME (1958) 213, 85.

Piot, B. M., \& Lietard, O. M., "Nature of Formation Damage in Reservoir Stimulation, in Economides," M. J. \& K. S. Nolte (eds.), Reservoir Stimulation, Schlumberger Education Services, Houston, Texas, 1987.

Production Systems, first edition. Upper Saddle River, New Jersey: Prentice Hall.

Van Everdingen, A. F. "The skin effect and its influence on the productive capacity of a well." Journal of petroleum technology 5.06 (1953): 171-176. 


\section{APPENDIX A}

\section{Example Calculations}

\section{Calculations for skin due to the damage zone $(\mathrm{Sd})$}

Using below equation to calculate $(\mathrm{Sd})$ :

$S_{d}=\frac{h}{h_{p}}\left[1-0.2 \frac{\left(r_{d}-r_{w}\right)}{h_{p}}\right]\left(\frac{k}{k_{d}}-1\right) \ln \frac{r_{d}}{r_{w}}$

$S_{d}=\frac{30}{10}\left[1-0.2\left(\frac{1.4-0.4}{10}\right)\left(\frac{200}{50}-1\right)\right] \ln \frac{1.4}{0.4}=11.05$

When $k_{d}=5 \mathrm{mD}$, then $S_{d}=143.65$ which is an increase of thirteen times and shows the permeability reduction has a larger effect on the skin than the penetration of damage.

Calculation of Crushed Zone Skin $\left(\boldsymbol{S}_{\boldsymbol{c z}}\right)$ :

$$
\begin{aligned}
S_{c z}=\frac{h}{L_{p e r f} n_{p}}\left(\ln \frac{r_{c Z}}{r_{p}}\right)\left(\frac{k}{k_{c z}}-\frac{k}{k_{d}}\right) \\
\quad=\frac{30}{(0.75)(52)}\left(\ln \left(\frac{0.69}{0.19}\right)\left(\frac{200}{5}-\frac{200}{50}\right)=35.71\right. \\
=\frac{30}{(0.75)(52)}\left(\ln \left(\frac{0.69}{0.19}\right)\left(\frac{200}{50}-\frac{200}{50}\right)=0\right.
\end{aligned}
$$

If the crushed zone permeability same as the damaged zone permeability then skin of crushed zone becomes zero as shown above.

\section{Calculation of Well Deviation $\operatorname{Skin}\left(\boldsymbol{S}_{\boldsymbol{\theta}}\right)$ :}

$\mathrm{kh}$ and $\mathrm{kv}$ are the horizontal and vertical permeabilities, respectively, $\theta$ is the angle and the permeability ratio $(\mathrm{kv} / \mathrm{kh})$ depends on the scale of the flow.

Can be calculated using equation below:

$\theta=\tan ^{-1}\left(\sqrt{\frac{K V}{K H} * \tan \theta}\right)$ 


$$
\begin{aligned}
& \theta=\tan ^{-1}\left[\sqrt{\frac{20}{200}} \tan (15)\right]=4.843 \\
& h_{d}=\frac{h}{r_{w}} \sqrt{\frac{K_{H}}{K_{V}}}=\frac{30}{0.4} \sqrt{\frac{200}{20}}=237.17 \\
& S_{\theta}=-\left(\frac{\theta}{41}\right)^{2.06}-\left(\frac{\theta}{56}\right)^{1.865} \log \left(\frac{h_{d}}{100}\right) \\
& \quad=-\left(\frac{4.843}{41}\right)^{2.06}-\left(\frac{4.843}{56}\right)^{1.865} \log \left(\frac{237.17}{100}\right)=-0.016
\end{aligned}
$$

$S_{\theta}$ Is small when $\theta=15$ degree 